\title{
Characterization of Thermal Stability and Heat Absorption for Suppressant Agent/Combustible Dust Mixtures via Thermogravimetric Analysis/Differential Scanning Calorimetry
}

\author{
Nicholas S. Reding ${ }^{(1)}$ and Mark B. Shiflett*(1) \\ Department of Chemical and Petroleum Engineering, University of Kansas, 1450 Jayhawk Boulevard, Lawrence, Kansas 66045, \\ United States
}

Supporting Information

\begin{abstract}
Combustible dusts continue to present a critical threat toward personnel and process equipment in a wide variety of bulk solids processing industries. The addition of noncombustible inert material to combustible dust mixtures, either through premixing or high-rate injection as the flame front begins to develop, is common practice for preventative inhibition or explosion protection via active suppression, respectively. Metal dusts in particular present an extremely reactive explosion risk due to amplified heat of combustion, burning temperature, flame speed, explosibility parameters $\left(K_{\mathrm{St}}\right.$ and $\left.P_{\max }\right)$, and ignition sensitivity. Establishment of proper prevention and mitigation designs for metal fuel deflagrations has posed challenging. The aim of this paper is to propose a method for the characterization of the inhibition

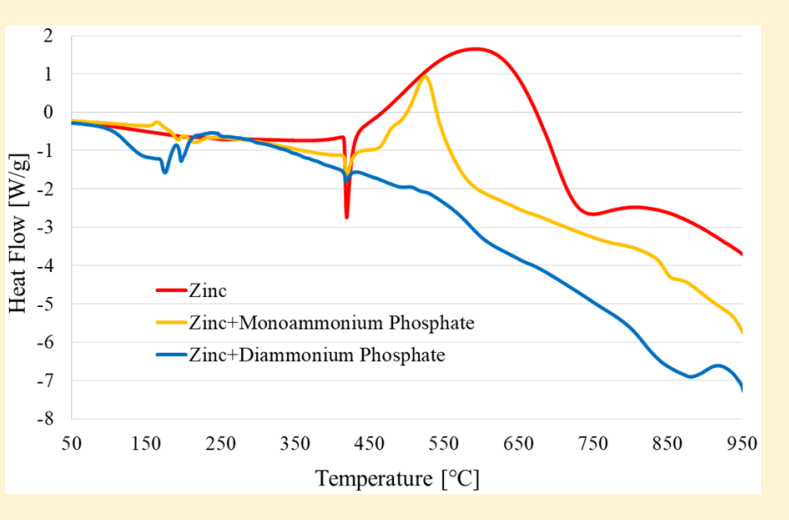
efficiency of five suppressant agents (sodium bicarbonate [SBC], potassium bicarbonate $[\mathrm{PK}]$, monoammonium phosphate [MAP], diammonium phosphate [DAP], and sodium chloride-based [Met-L-X]) when mixed with both organic (cornstarch) and metallic (zinc) fuels. For each 1:1 wt \% fuel/agent mixture, thermal stability and heat absorption have been evaluated using thermogravimetric analysis (TGA) and differential scanning calorimetry (DSC).
\end{abstract}

\section{INTRODUCTION}

Metal dust deflagrations and subsequent explosions continue to plague the solids processing industry. At the Hayes Lemmerz International-Huntington Inc. facility in Indiana in 2003, ignition and flame propagation within an aluminum scrap dust collection equipment line led to one fatality and several injuries. ${ }^{1}$ Triggered by frictional heating or sparks in a defective blender unit, three fatalities and one serious injury followed a zirconium dust explosion in December of 2010 at AL Solutions Inc. in New Cumberland, WV. ${ }^{2}$ In August of 2014, a series of devastating aluminum-alloy dust explosions at a metal polishing plant in Kunshan, China, resulted in 146 fatalities and 114 injuries. ${ }^{3}$ Upon ignition of a suspended dust cloud, metal dust fuels are capable of generating exceedingly high flame temperatures and substantial rates of pressure rise. Reding and Shiflett describe the full extent of the complexities and spontaneity associated with sustained metal dust combustion in a recent review article. ${ }^{4}$ Taveau further illustrates the distinct combustion characteristics of metallic fuels and comments on the resultant challenges in designing effective explosion protection solutions. ${ }^{5}$ As shown in a multitude of extensive comprehensive works, metal dust combustion regimes are considered to be extremely dangerous hazards unless proper prevention and/or protection techniques are established. ${ }^{6,7}$
The development of inhibition materials compositionally suitable for inerting or mitigation of combustible dust deflagrations has been a thoroughly investigated topic of study. Industry commonly introduces inert additives to combustible dusts using primarily two methods. The first approach involves premixing inert material with the combustible dust, with the objective of explosion prevention or inhibition. In this case, even if sufficient oxidizer content and ignition energy are available, the system will not combust due to dilution of the fuel below the minimum flammability concentration as defined by the fuel type. However, this preventative approach has drawbacks. One must closely monitor the process, ensuring that the inert and fuel are constantly well-mixed such that the minimum inerting concentration (MIC) is maintained throughout each enclosure volume. Ideal mixing may pose challenging if the fuel and agent have substantially different particle size distributions, which can lead to segregation and agglomeration within the mixture. In addition, the customer may not be willing to sacrifice the purity of the product by contamination with an inert material. ${ }^{6}$

Received: December 11, 2018

Revised: February 15, 2019

Accepted: February 19, 2019

Published: February 19, 2019 
The second approach involves timely, rapid injection of suppressant agent into the combustion volume at the onset of the deflagration, with the intention of limiting the maximum observed system pressure and inducing deflagration extinction. This technique must be properly designed based on the appropriate capabilities of the hardware (time delay between detection and system activation, injection distribution profile, discharge rate, discharge duration, etc.) and is restricted by its specificity to the application in question.

Inert additives prevent propagation of sustained deflagration through the protected volume via physical or chemical methods. Physical suppressants, such as rock dust, operate by absorbing both thermal and radiant energy from the developing deflagration and by diluting the fuel and oxygen content per unit volume. Energy removed from the ongoing combustion reaction significantly reduces the rate at which unburnt particles are preheated. As the concentration of physical inert increases, the system has less free energy available for unburnt fuel particles to preheat, thus impeding combustion growth and further propagation of the flame front. Depending on the composition of the inhibition material, thermal decomposition may additionally release water and inert gases (such as carbon dioxide emitted during calcium carbonate decomposition), which act as heat sinks and heighten the physical inerting mechanism. Chemical inhibition implies that the suppressant agent directly hinders the combustion reaction kinetically through disruption of branch chain reactions and detention of free combustion radicals. Certain dry powder suppressant agents, such as sodium bicarbonate and monoammonium phosphate, provide flame extinction benefits via both physical and chemical means. ${ }^{8}$

The efficiency of a dust explosion inhibitor improves with equivalent increase in three key properties of the agent: specific heat capacity, thermal conductivity, and absorptivity. ${ }^{8}$ Heat capacity at the particle level is closely related to the characteristics of the inertant chemical composition; however, heat capacity on a bulk scale is directly proportional to the amount of inert introduced into the application. A higher concentration of inert material within the fuel/agent mixture effectively increases the heat capacity of the system. Thermal conductivity represents the rate at which heat passes through a given material and is measured as the reciprocal of resistance to heat flow. The degree of heat absorptivity is a function of the inert particle surface area, with a larger particle surface area promoting greater rates of heat absorption. Surface area itself is a function of both particle shape and size. Irregular, small-sized suppressant agent particles are identified as having greater surface areas. Following the analysis of experiments with coal and rock dust mixtures (fuel and inhibitor, respectively) in a Siwek $20 \mathrm{~L}$ spherical vessel, Dastidar et al. conclude that decreased suppressant particle sizes yield a reduction in the MIC required to prevent initiation of oxidative combustion. ${ }^{9}$ The aforementioned suppressant properties are applicable to the performance of all solid inhibitors. However, the effectiveness of the material for inerting or suppressive mitigation is also dependent on the properties of the fuel (combustible dust composition, fuel reactivity, particle size, degree of surface oxidation, and suspended concentration). This presents an issue when dealing with reactive metal dust fuels which commonly exhibit extremely high adiabatic flame temperatures and significant heats of combustion.

In a separate review, Amyotte discusses complementary parameters influencing the efficacy of noncombustible dusts for the inerting (prevention) or suppression (mitigation) of dust explosions. The variables under investigation include factors representative of the inert material (composition, particle size) and of the application (coexistence of flammable gas, ignition energy, size/geometry of combustion vessel). ${ }^{10}$ Even though the large-scale application factors indeed play a role in assessment of the agent's performance, it must be noted that the motivation for this paper is to examine the effect of material composition on heat of absorption and combustion rate inhibition during fuel decomposition. Inertant powders with varying compositions have fundamental differences in their specific heats, heats of reaction, decomposition temperature, and decomposition rate. Inhibition materials with high heat capacities act through physical means by absorbing thermal energy away from the developing deflagration and restraining continued propagation to other unburnt regions outside of the combustion zone. Depending on the onset of inert decomposition and rate of endothermic decomposition over a specific temperature range, certain suppressant agents may also exhibit improved performance due to extended "residence time" within the fuel combustion zone.

\section{INERTING AND MITIGATION STUDIES ON KEY INERT MATERIALS}

2.1. Carbonates (Sodium Bicarbonate and Potassium Bicarbonate). The two carbonate materials tested as dry powder inhibitors were sodium bicarbonate $\left(\mathrm{SBC} ; \mathrm{NaHCO}_{3}\right)$ and potassium bicarbonate $\left(\mathrm{PK} ; \mathrm{KHCO}_{3}\right)$. Sodium bicarbonate was analyzed in the form of dry chemical inhibition agent known as "Plus-Fifty C Dry Chemical". Potassium bicarbonate was analyzed in the form of an inhibition agent known as "Purple-K Dry Chemical". The composition and vendor for both of these inert materials is discussed in detail in section 3.

With the use of $20 \mathrm{~L}$ sphere testing, Jiang et al. investigated the effects of sodium bicarbonate particle size on the mitigation and preventative inerting of $5 \mu \mathrm{m}$ and $30 \mu \mathrm{m}$ aluminum dust explosions. ${ }^{11}$ This study found a gradual decrease in maximum explosion pressure through increased $\mathrm{NaHCO}_{3}$ concentrations and at smaller suppressant particle sizes. For a $5 \mu \mathrm{m}$ aluminum dust concentration of $300 \mathrm{~g} / \mathrm{m}^{3}$, the $\mathrm{MIC}$ of $\mathrm{NaHCO}_{3}$ was found to be $1900 \mathrm{~g} / \mathrm{m}^{3}$ and $2100 \mathrm{~g} /$ $\mathrm{m}^{3}$ for suppressant particle diameters of 53 to $75 \mu \mathrm{m}$ and 110 to $212 \mu \mathrm{m}$, respectively. For a $30 \mu \mathrm{m}$ aluminum dust concentration of $800 \mathrm{~g} / \mathrm{m}^{3}$, the MIC of $\mathrm{NaHCO}_{3}$ was found to be $1200 \mathrm{~g} / \mathrm{m}^{3}$ and $1000 \mathrm{~g} / \mathrm{m}^{3}$ for suppressant particle diameters of 53 to $75 \mu \mathrm{m}$ and 110 to $212 \mu \mathrm{m}$, respectively. The inhibition mechanism for sodium bicarbonate occurs in four determinant steps. First, suppressant particles undergo heating due to initiated fuel combustion. Second, the agent begins to decompose. Third, gas and solid phase decomposition products are produced. Fourth, combustion propagation inhibition occurs. The total duration of these four events is designated by $t_{i}$. In the case of $5 \mu \mathrm{m}$ aluminum combustion, since the burning time $\left(t_{\mathrm{b}}\right)$ is exceedingly brief in comparison to the aforementioned $\mathrm{NaHCO}_{3}$ inhibition process $\left(t_{i}\right)$, particle size reduction had a minimal effect on lowering of the MIC (9.5\% decrease in MIC for $5 \mu \mathrm{m}$ aluminum; $16.7 \%$ decrease in MIC for $30 \mu \mathrm{m}$ aluminum). For situations such as this, in which $t_{\mathrm{b}} \ll t_{\mathrm{j}}$, the inhibition of flame becomes increasingly dependent on thermal mechanisms to account for the relatively slow rate of chemical inhibition modes. Although the chemical decomposition duration may not be optimum for 
smaller fuel particle sizes, $\mathrm{NaHCO}_{3}$ nevertheless appears to play a pivotal role in impeding gas phase aluminum combustion propagation. Sodium bicarbonate decomposition products reduce the fuel burning rate and obstruct complete metal oxidation through $\mathrm{O}_{2}$ and $\cdot \mathrm{O}$ radical diminution.

In another study, Chen et al. investigated the effect of sodium bicarbonate with varying granulometric distributions (particle dispersity) on $15 \mu \mathrm{m}$ aluminum dust cloud propagation intensity. Inerting through the addition of suppression agents with wider particle size dispersity yielded limited flame temperatures, destabilized the overall combustion reaction, and inhibited development of the combustion reaction front. Fluctuating suppressant agent agglomeration patterns generated an increasingly nonuniform preheat zone thickness and decreased flame speeds when compared to agents characterized by a specific particle diameter. ${ }^{12}$

Through both burner and $20 \mathrm{~L}$ sphere analysis methods, Rockwell and Taveau investigated the influence of SBC on hybrid flame propagation. In this case, the hybrid mixture under evaluation consisted of $27 \mu$ m mean particle size iron powder and gaseous methane-air with an equivalence ratio of one. At fuel concentrations between 25 and $75 \mathrm{~g} / \mathrm{m}^{3}$, this study found a noticeable decrease in turbulent burning velocity and maximum rate of pressure rise $\left(K_{\mathrm{St}}\right)$ upon addition of $27 \mu \mathrm{m}$ SBC at concentrations between $25 \%$ and $75 \%$ of the initial iron concentration. ${ }^{13}$ During SBC decomposition, the agent effectively interferes with the expansion of the hybrid flame zone by releasing water vapor and carbon dioxide decomposition products, which participate thermally as heat sinks.

Going and Snoeys examine and contrast the efficacy of inert powders SBC and PK for the mitigation of silicon and aluminum metal dust deflagrations using $1 \mathrm{~m}^{3}$ explosion suppression testing. ${ }^{14}$ Following explosibility testing at optimum fuel concentration, silicon dust demonstrated a $K_{\mathrm{St}}$ of $120 \mathrm{barg} \cdot \mathrm{m} / \mathrm{s}$ and a maximum pressure developed during a contained deflagration $\left(P_{\max }\right)$ of 8.16 barg. At $1000 \mathrm{~g} / \mathrm{m}^{3}$ suspended silicon concentration, deflagration suppression testing (at 0.035 barg activation pressure) demonstrated similar total suppressed pressures (TSP) of 0.33 and 0.27 barg for SBC and $\mathrm{PK}$, respectively, at $2.3 \mathrm{~kg} / \mathrm{m}^{3}$ agent concentration. Even at increased PK concentration of $4.5 \mathrm{~kg} /$ $\mathrm{m}^{3}$, results indicate no further enhancement of the suppression performance. On the contrary, the subsequent TSP under these conditions increased slightly due to greater injection pressures, implying that the protected volume was fully suppressed at $2.3 \mathrm{~kg} / \mathrm{m}^{3}$ agent concentration. Although minimal differences between SBC and PK suppression performance were apparent for silicon dust deflagration mitigation, the testing for aluminum dust $\left(K_{\mathrm{St}}=300 \mathrm{barg}\right.$. $\mathrm{m} / \mathrm{s}, P_{\max }=8.50 \mathrm{barg}$ ) proved aluminum deflagrations more difficult to suppress but displayed noticeable trends in agent performance. For aluminum dust at $1750 \mathrm{~g} / \mathrm{m}^{3}$ fuel concentration ( 0.035 barg activation pressure), SBC and PK at $4.5 \mathrm{~kg} / \mathrm{m}^{3}$ agent density yielded TSP values of 2.05 barg and 1.25 barg, respectively. Although PK appears to be more effective at $4.5 \mathrm{~kg} / \mathrm{m}^{3}$, both $\mathrm{SBC}$ and $\mathrm{PK}$ required a much higher agent concentration in order to induce complete suppression (at $9.1 \mathrm{~kg} / \mathrm{m}^{3}$, TSPs for SBC and PK were reported at $0.84 \mathrm{barg}$ and $0.89 \mathrm{barg}$, respectively). On a largescale application setting, the effectiveness of the agent toward complete suppression of metal dust deflagrations depends on additional factors other than the agent composition. Bulk material flow limitations such as inverse velocity at specific throw distances, discharge velocity, and injection profile will also exhibit an appreciable influence on system performance and the ability of the agent to suppress deflagrations at higher fuel concentrations. ${ }^{15,16}$ Aside from this work, PK has not been investigated as extensively as SBC from an explosion inhibition standpoint; however, it does demonstrate adequate inerting performance when employed as a fire suppressant. ${ }^{17}$

2.2. Phosphates (Monoammonium Phosphate and Diammonium Phosphate). The two phosphate materials tested as dry powder inhibitors were monoammonium phosphate (MAP; $\mathrm{NH}_{4} \mathrm{H}_{2} \mathrm{PO}_{4}$ ) and diammonium phosphate (DAP; $\left.\left(\mathrm{NH}_{4}\right)_{2} \mathrm{HPO}_{4}\right)$. MAP was considered as the inhibition agent known as "ABC Dry Chemical Fire Extinguishant". The composition and vendor for both of these inert materials will be discussed in detail in section 3 .

Flame retardants containing nitrogen compounds are excellent options for preventative inerting of bulk combustible solids. Nitrogen and nitrogen-phosphorus based solid inertants and their decomposition products exhibit substantially lower toxicity, decreased corrosion, and increased efficiency in comparison to common metallic hydroxide alternatives. The relatively low activity of metal hydroxide flame retardants necessitates higher minimum concentrations to meet equivalent inhibition performance. Utilized in many polymer and plastic manufacturing industries, nitrogen-based compounds possess high decomposition temperature, allowing the inert material to be recycled within the process without concern of potential degradation of the physical properties of the polymeric material. Use of halogen flame retardant puts the plastic production process in jeopardy by limiting the potency of polymer stabilizer additives. ${ }^{18}$

Studies by Jiang et al. compared the inhibition of $5 \mu \mathrm{m}$ and $30 \mu \mathrm{m}$ aluminum dust explosions with MAP and SBC. As the concentration of inert material increased, the flame front became increasingly irregular, resulting in restricted flame propagation velocity. At a constant $1000 \mathrm{~g} / \mathrm{m}^{3}$ fuel concentration, MAP exhibited a greater impact on average flame propagation velocity reduction relative to SBC. Flame propagation through a $30 \mu \mathrm{m}$ aluminum dust cloud was fully inhibited by the addition of MAP at an agent concentration of $1300 \mathrm{~g} / \mathrm{m}^{3}$, while SBC did not completely impede the deflagration until the agent concentration exceeded $2200 \mathrm{~g} /$ $\mathrm{m}^{3}$. Similar performance trends were measured for propagation inhibition through a $5 \mu \mathrm{m}$ aluminum dust cloud. MAP was able to fully suppress the propagation at an agent concentration of $1600 \mathrm{~g} / \mathrm{m}^{3}$, whereas the minimum inerting concentration for SBC was not obtained, even at agent concentrations as high as $2200 \mathrm{~g} / \mathrm{m}^{3}$. Both agents utilize physical endothermic decomposition within the flame front, absorbing combustion heat used to volatilize nearby particles in the preheat zone. The presence alone of the inert particles within the dispersed fuel/ air cloud adds resistance to the direct diffusion of oxygen, blocking further gas-phase single element oxidative combustion. Using kinetic modeling techniques for stoichiometric mixtures of aluminum/air and inhibitor, Jiang et al. demonstrate that the MAP inhibition mechanism more effectively competes for oxygen and oxygen radicals, which chemically interrupts the combustive aluminum oxidation and limits temperature rise within the mixture. ${ }^{19}$ Luo et al. examined the effects of ammonia on methane gas combustion dynamics and arrived at similar conclusions regarding the suppressive mechanism of ammonia compounds. For specific volumes of air mixed with of $7,9.5$, and 11 vol \% methane, 
increased ammonia content correlated directly with narrowed fuel explosibility limits, reduced maximum explosion pressures, and decreased rates of pressure rise. Ammonia and amino groups readily consume radicals required to sustain methane combustion due to significantly lower activation energies when compared to methane and methyl group chain reactions. ${ }^{20}$

In other inhibitor inerting investigations, Chatrathi and Going measured the MIC of SBC and MAP with a variety of fuels. At constant ignition energy and system turbulence, SBC and MAP demonstrated similar minimum agent concentrations required to prevent the development of the flame front $(625 \mathrm{~g} /$ $\mathrm{m}^{3}$ and $875 \mathrm{~g} / \mathrm{m}^{3}$ for SBC and MAP, respectively) at the ideal concentration of suspended cornstarch. However, even at inerting concentrations as high as $2750 \mathrm{~g} / \mathrm{m}^{3}$, SBC and MAP were both unable to prevent sustained deflagration growth upon ignition of aluminum powder at optimal fuel concentration. $^{8}$

Studies by Moore compare the efficacy of multiple dry chemical powder suppressants, including MAP, SBC, and Dessikarb (food-grade sodium bicarbonate), for the mitigation of maize dust $\left(K_{\max }=200 \mathrm{barg} \cdot \mathrm{m} / \mathrm{s}\right)$ deflagrations via active explosion suppression. At various system activation pressures between 0.05 and 0.3 barg, MAP continued to demonstrate amplified suppression efficiency, as well as equal or lower reduced pressures following complete agent injection into the protected volume. $^{21}$ However, tests performed by Amrogowicz and Kordylewski expose conflicting conclusions regarding suppression of organic fuels. The effectiveness of MAP and SBC were compared for both inerting and suppression of a variety of deflagration fuels (melamine, wheat flour, wood dust, and coal dust). MAP was found to be more effective for preventative inerting of organic deflagrations, while SBC was more effective for explosion mitigation application. ${ }^{22}$

Unlike MAP, DAP has not been thoroughly studied for either preventative explosion inerting or explosion mitigation. DAP is a suitable fire retardant additive material and shows potential as an effective explosion inhibitor based on its substantial energy absorption capabilities upon endothermic decomposition to ammonia and water. ${ }^{23}$ Castellanos et al. evaluated the efficiency of MAP and DAP for the inhibition of cornstarch combustion propagation using techniques such as thermogravimetric analysis (TGA), differential scanning calorimetry (DSC). Performed under a nitrogen atmosphere and at a 1:1 wt \% fuel to agent mixture ratio, analysis of DSC profiles demonstrated that the addition of MAP and DAP limited the heat released during fuel decomposition by 65.5 and $71.5 \%$, respectively. In addition, upon constant heating of the cornstarch and MAP mixture, it was apparent that MAP induced a shift in the onset of exothermic decomposition to lower temperatures, suggesting that this agent may be better suited for explosion mitigation and less appropriate for preventative inerting. Explosibility testing in the $36 \mathrm{~L}$ combustion vessel found that DAP yields reduced fuel $K_{\mathrm{St}}$ at all inert loading weights/particles sizes and depicts DAP as having greater cornstarch combustion inhibition performance. The amplified heat absorption capacity of DAP can be explained in part by the increased ammonia content released during inertant decomposition in comparison to that of MAP. The higher vapor pressure of gaseous inert decomposition products generates an oxygen dilution mechanism which reduces the rate of sustained fuel combustion by limiting oxygen diffusion into the flame zone. ${ }^{24}$
2.3. Sodium Chloride-Based Suppressant Agent. The final inhibitor material investigated within the scope of this study is compositionally based on sodium chloride $(\mathrm{NaCl})$. The complete composition for the sodium chloride-based suppression agent (in the form of Met-L-X powder) will be discussed in further detail within section 3. Met-L-X was selected for this study due to its well-documented effectiveness for the suppression of metal fires.

As reported by Zalosh, Met-L-X is a certified Class D fire suppression agent, capable of extinguishing a variety of metal hydride fires. ${ }^{25}$ According to NFPA 484, Met-L-X is the preferred extinguishing agent for the suppression of combustible metal fires involving the following pure metals: alkali metals, aluminum, magnesium, niobium, tantalum, titanium, and zirconium. ${ }^{26}$ Unlike fire suppression agents consisting of water, carbon dioxide, or halogenated material, Met-L-X does not exhibit reactivity concerns when inhibiting metal hydride fires. Met-L-X is composed primarily of sodium chloride and a thermoplastic polymer. The polymer additive increases sodium chloride cohesion and allows for more complete agent coverage of the burning metal to prevent further diffusion of oxygen. Many Class D agents such as Met-L-X demonstrate efficiency in extinguishing the initial metal fire; however, they differ in their inability to produce prolonged cooling effects following the preliminary incident, which allows for the possibility of secondary ignition upon reintroduction to the oxidizing atmosphere. ${ }^{25}$

Sodium chloride has been investigated for fire suppression, but has seldom been analyzed for use as an explosion suppressant. Cao et al. explored the influence of $\mathrm{NaCl}$ on methane/air explosion suppression using ultrafine water mist in closed vessel combustion experiments. Following the addition of $5 \% \mathrm{NaCl}$ by mass, the water mist suppression technique was noticeably improved due to a reduction in radiation heat transfer and decreased combustion temperatures within the flame and preheat regions. Additionally, Cao et al. demonstrated that this consequence ultimately resulted in inhibited reaction kinetics and underdeveloped flame propagation velocities. The presence of sodium and chloride ions within the protected volume actively capture free radicals $(\cdot \mathrm{O}$, $\mathrm{H}$, and $\cdot \mathrm{OH}$ ) which would normally participate in the chain reactions of persistent methane explosion propagation. ${ }^{27}$

\section{INSTRUMENT, MATERIALS, AND EXPERIMENTAL PROCEDURE}

Two analytical techniques were utilized to assess the performance of the aforementioned agents as combustion inhibitors. Thermogravimetric analysis (TGA) measures the sample weight change as a function of temperature during decomposition under air or nitrogen atmosphere. Differential scanning calorimetry (DSC) was used to determine the onset of thermal decomposition and to measure the heat released (or absorbed) during sample exothermic (or endothermic) decomposition. DSC also provides an opportunity to compare the relative capability of the inert material to absorb heat away from the fuel combustion.

The TGA/DSC instrument (TA Instruments-SDT Q600) provided simultaneous measurement of weight change and differential heat flow from ambient temperatures to a maximum operating temperature of $1500{ }^{\circ} \mathrm{C}$. All experiments utilized $90 \mu \mathrm{L}$ alumina (ceramic) sample pans and were performed under air at atmospheric operating pressure, with a constant heating rate of $10{ }^{\circ} \mathrm{C} / \mathrm{min}$. All equipment signals, 
including TGA weight, DTA baseline, heat flow, temperature, and cell constant, were recalibrated regularly to ensure accuracy of the measurements. Zinc was the metal standard used for all temperature calibrations, and calorimetric precision was confirmed to be within $\pm 2 \%$. Average sample loading weights are provided in Table 1, with a fuel to inhibitor

\section{Table 1. Average TGA/DSC Sample Loading Weights}

$\begin{array}{lc}\text { sample type } & \text { loading weight }[\mathrm{mg}] \\ \text { inhibitor } & 10 \\ \text { fuel } & 10 \\ \text { mixture }^{a} & 20\end{array}$

${ }^{a}$ Note: Regardless of total sample weight, mixture solids composition was maintained at a 1:1 ratio by weight. Slight variation in total loading weight is acceptable, as all TGA/DSC results are appropriately scaled by mass.

mixture ratio held constant at $1: 1$ by weight. Each mixture trial was thoroughly blended during sample preparation prior to loading; however, the authors acknowledge nonuniform solids mixing as a potential degree of uncertainty. To account for this, all trials were duplicated a minimum of three times to ensure the reproducibility of results.

Food grade cornstarch $\left(\mathrm{C}_{6} \mathrm{H}_{10} \mathrm{O}_{5}\right)_{n}$ was purchased from Ingredion (CASRN 9005-25-8). Cornstarch was selected as the organic fuel for the purpose of establishing a baseline for comparison. Large-scale suppression and preventative inerting results with cornstarch as the fuel are widely publicized within the explosion protection industry. Zinc powder (Zn-101; CASRN 7440-66-6) was purchased from Atlantic Equipment Engineers, a division of Micron Metals, Inc. Zinc was selected as the metal for this study because its melting and boiling temperatures ( 420 and $907^{\circ} \mathrm{C}$, respectively) fit well within the maximum temperature limitations of the instrument. In comparison to metals such as aluminum and magnesium, zinc is considered to be a relatively low-reactive metal from an explosion protection design standpoint; nevertheless, zinc is a relevant metal dust to investigate based on its growing prevalence in industry. On the basis of application data categorized by Fike Corporation between 2015 and 2018, greater than $90 \%$ of all metal dust active suppression/isolation systems involve either iron (steel), aluminum, or zinc fuels. Pure metal zinc powder was analyzed, rather than alloy-type metals, to avoid misidentification of the combustion temperature range.

The carbonate-based dry chemical suppressant agents, "PlusFifty C Dry Chemical" (product code 009336) and "Purple-K Dry Chemical" (product code 009335), were both purchased from Ansul. "Plus-Fifty C Dry Chemical" is composed primarily of SBC (CASRN 144-55-8), with trace amounts of calcium carbonate, attapulgite, and other inert flow-promoting additives. "Purple-K Dry Chemical" is composed primarily of PK (CASRN 298-14-6), with trace amounts of mica, attapulgite, and other inert flow-promoting additives. The phosphates, MAP (CASRN 7722-76-1) and DAP (CASRN 7783-28-0), were purchased from Amerex and Parchem, respectively. MAP comes in the form of "ABC Dry Chemical Fire Extinguishant" (product code $\mathrm{CH} 555$ ), which contains 80-98\% MAP and a trace amount of flow agents and chemical additives. The fire suppression agent to be investigated, Met-L$\mathrm{X}$, was purchased from Ansul. Met-L-X (product code 009328) is a mixture consisting of $80-90 \%$ sodium chloride (CASRN
557-04-0), 1-2.5\% magnesium distearate (CASRN 7647-145 ), and trace amounts of heat absorbent additives.

All fuels involved in this study (cornstarch and zinc) underwent explosibility testing (without inhibitors) in the Fike $1 \mathrm{~m}^{3}$ spherical combustion test vessel, according to the international standard ASTM E1226. ${ }^{28}$ The combustion chamber consists of two hemispherical sections, with an overall design strength of 21 bar gauge (barg). Following a full explosibility workup of both fuels (multiple unsuppressed shots at increasing fuel content), optimum nominal dust concentrations were determined as follows: $750 \mathrm{~g} / \mathrm{m}^{3}$ for cornstarch and $2250 \mathrm{~g} / \mathrm{m}^{3}$ for zinc. Results from this testing include maximum explosion pressure $\left(P_{\max }\right)$ and deflagration index $\left(K_{\mathrm{St}}\right)$, which is proportional to the maximum rate of pressure rise within the contained volume. Both of these explosibility parameters were measured at ideal suspended fuel concentration and provide the reader an assessment of the fuel severity potential. The results are reported in Table 2 . Ignition delay was maintained at $600 \mathrm{~ms}$. Ignition energy was provided using two 5-kilojoule chemical igniters.

Table 2. Fuel Explosibility Results at Optimum Suspended Concentration, Reported via Analysis in $1 \mathrm{~m}^{3}$ Sphere Combustion Vessel

\begin{tabular}{lcc}
\multicolumn{1}{c}{ fuel } & $K_{\mathrm{St}}[\mathrm{barg} \cdot \mathrm{m} / \mathrm{s}]$ & $P_{\max }[\mathrm{barg}]$ \\
\hline cornstarch & 196 & 8.48 \\
zinc & 97 & 5.97 \\
\hline
\end{tabular}

All agents (SBC, PK, MAP, DAP, Met-L-X) were ground and sieved to maintain a consistent particle size distribution and limit the degree of particle dispersity. A laser diffraction particle size analyzer (CILAS 990) was used to capture the mean postgrinding particle sizes, as reported in Table 3 . The

Table 3. Mean Particle Sizes of Agents and Fuels To Be Tested

\begin{tabular}{|c|c|}
\hline & mean particle size $(\mu \mathrm{m})$ \\
\hline \multicolumn{2}{|l|}{ Inhibitor } \\
\hline SBC & 23.8 \\
\hline PK & 18.9 \\
\hline MAP & 15.3 \\
\hline DAP & 16.5 \\
\hline Met-L-X & 17.6 \\
\hline \multicolumn{2}{|l|}{ Fuel } \\
\hline cornstarch & 15.3 \\
\hline zinc & 4.0 \\
\hline
\end{tabular}

mean inhibitor particle size for all agents was maintained between 15 and $30 \mu \mathrm{m}$ in order to eliminate particle size as a parameter affecting inhibitor performance. Figure 1 illustrates the particle size distribution of $\mathrm{SBC}$, as a reference. The particle size distributions for all other agents and fuels, as well as relevant statistical data, are provided in Appendix C. The "as-tested" mean particle sizes of the fuels are also shown in Table 3.

\section{RESULTS AND DISCUSSION}

4.1. Fuel TGA/DSC Profiles and Predicted Inhibitor Efficiencies. During experimental heating at a constant ramp rate, suppressant agents exhibit endothermic decomposition. Heat flow signatures provide a predictive technique for 


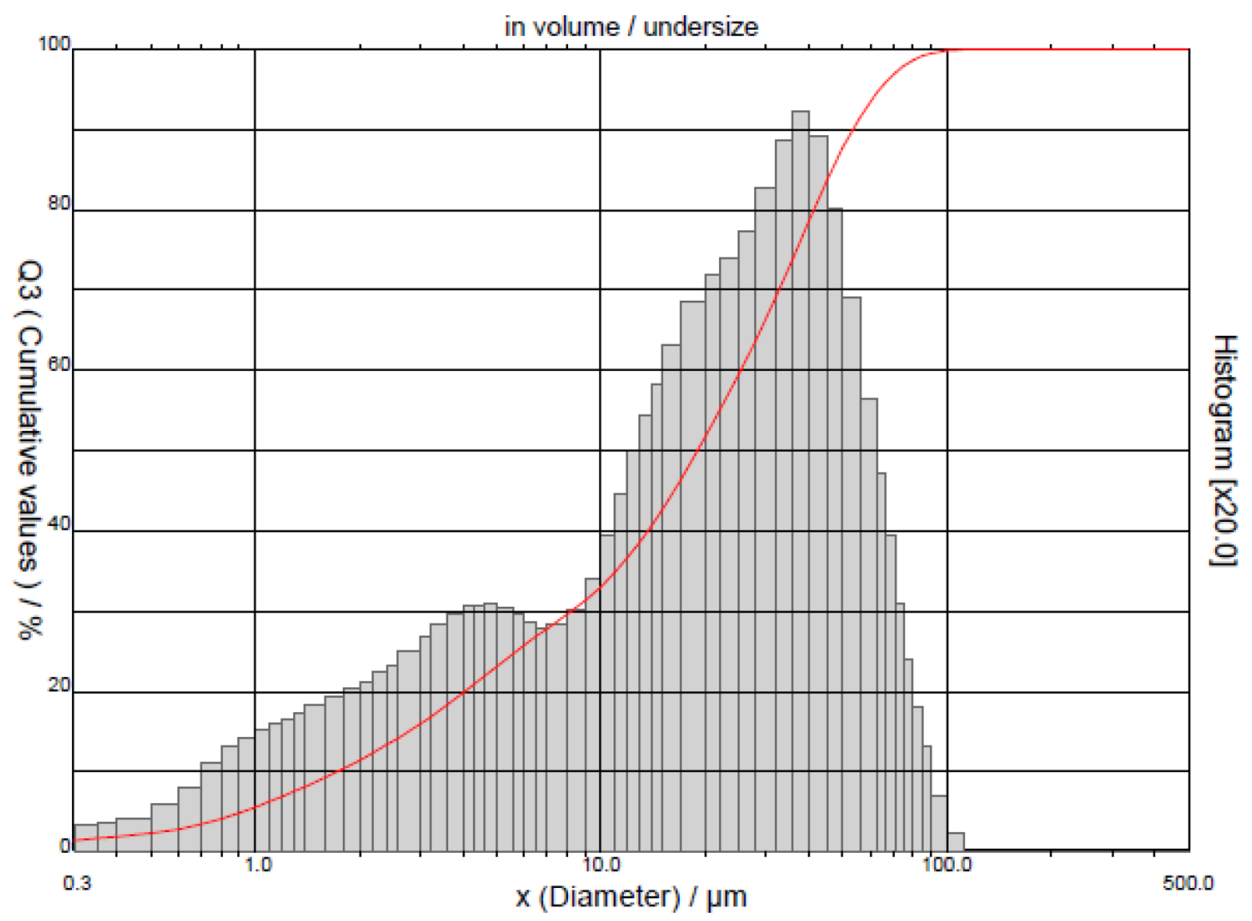

Figure 1. Postgrinding particle size distribution for sodium bicarbonate [SBC].

characterizing the performance of an agent based on its "capacity" to absorb heat. This method was used to rank the effectiveness of the suppressant agents with respect to their ability to absorb heat away from both organic and metallic dust combustion.

For inhibition agents, the area above the endothermic curve represents the amount of heat absorbed $(\mathrm{J} / \mathrm{g})$ during decomposition. For fuels, the area beneath the exothermic curve measures the quantity of heat released $(\mathrm{J} / \mathrm{g})$ during oxidative combustion. This quantity can be obtained through integration of the fuel DSC signature over the temperature range specific to the fuel combustion zone. For the organic fuel, cornstarch, this combustion region occurs from approximately 250 to $575{ }^{\circ} \mathrm{C}$ and is illustrated by TGA and DSC shown in Figures 2 and 3, respectively. The TGA profile for cornstarch combustion depicts products commonly volatilized during organic fuel decomposition. The first weight

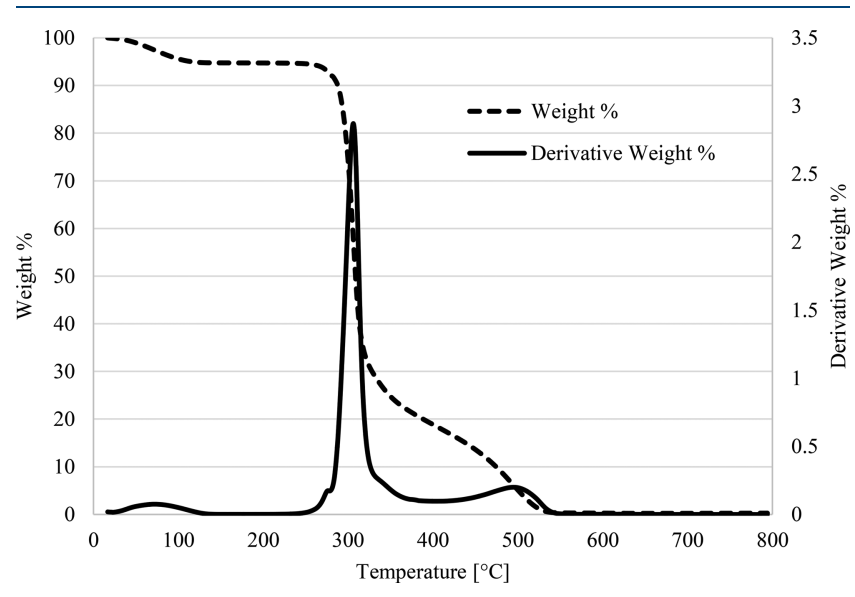

Figure 2. Thermogravimetric profile for cornstarch fuel. Increase in temperature, from room temperature to $800{ }^{\circ} \mathrm{C}$, at a constant $10^{\circ} \mathrm{C} /$ min heating rate (in air).

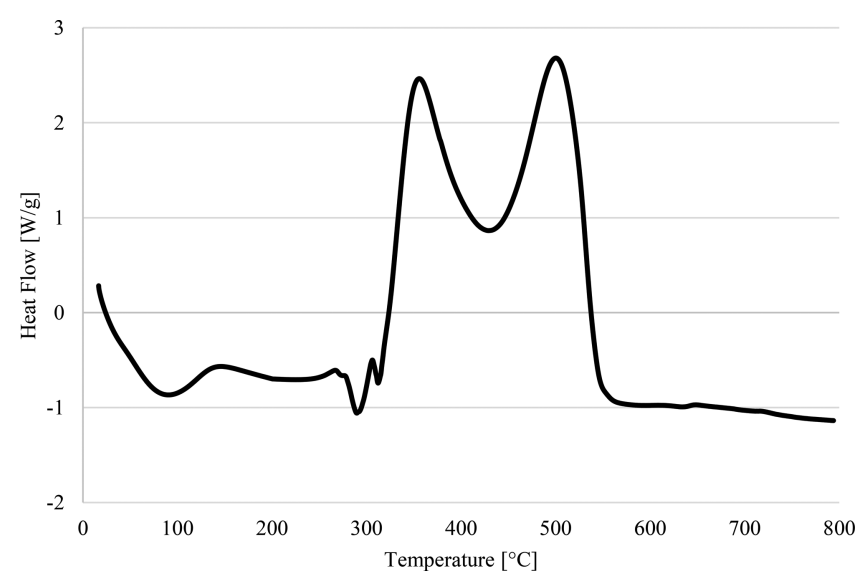

Figure 3. Differential scanning calorimetry profile for cornstarch fuel. Increase in temperature, from room temperature to $800{ }^{\circ} \mathrm{C}$, at a constant $10^{\circ} \mathrm{C} / \mathrm{min}$ heating rate (in air).

loss peak, at approximately $100{ }^{\circ} \mathrm{C}$, represents the evaporation of water from the sample (1.34 wt \% moisture content). Reliant on the dynamic oxygen availability at the reaction surface, the release of complete and incomplete combustion volatiles $\left(\mathrm{CO}_{2}\right.$ and $\mathrm{CO}$, respectively) occurs next with maximum derivative weight percentages at approximately 305 and $490{ }^{\circ} \mathrm{C}$, accounting for approximately $95 \%$ of the total initial sample weight. Integration of the DSC profile over the fixed combustion region for cornstarch yielded $659 \pm 41 \mathrm{~J} / \mathrm{g}$ of heat emitted during $\left(\mathrm{C}_{6} \mathrm{H}_{10} \mathrm{O}_{5}\right)_{n}$ oxidation.

The zinc combustion mechanism is distinct in comparison to other pure metals, in that flame propagation occurs exclusively in the liquid phase. ${ }^{29}$ Therefore, the combustion region of interest for zinc powder can be narrowed to the temperatures immediately succeeding the onset of melting, from approximately 420 to $750{ }^{\circ} \mathrm{C}$, as shown by TGA and DSC analysis in Figures 4 and 5, respectively. On the basis of 


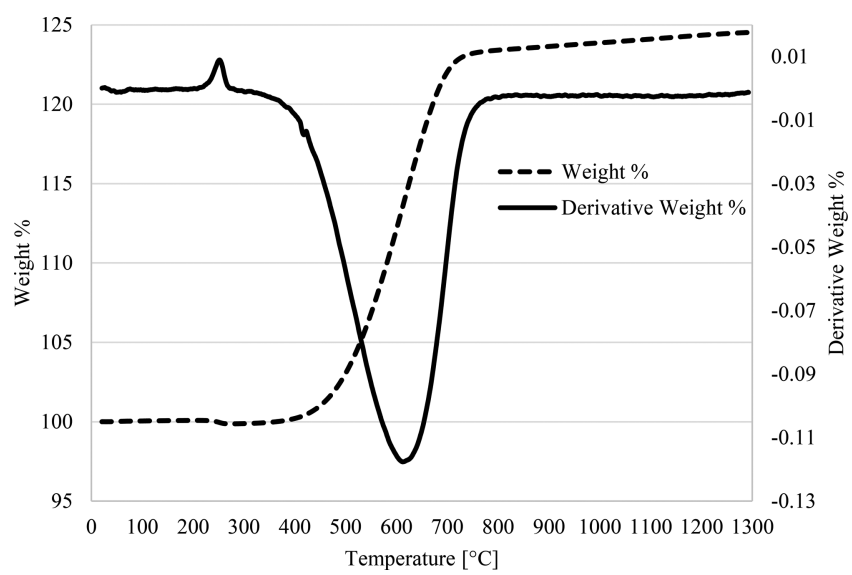

Figure 4. Thermogravimetric profiles for zinc powder fuel. Increase in temperature, from room temperature to $1300{ }^{\circ} \mathrm{C}$, at a constant 10 ${ }^{\circ} \mathrm{C} / \mathrm{min}$ heating rate (in air).

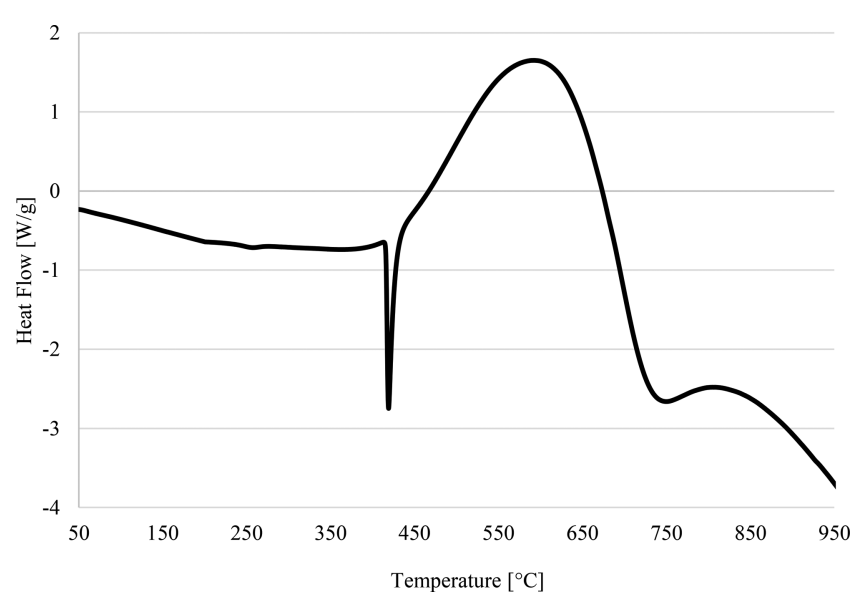

Figure 5. Differential scanning calorimetry profiles for zinc powder fuel. Increase in temperature, from 50 to $950{ }^{\circ} \mathrm{C}$, at a constant $10^{\circ} \mathrm{C} /$ min heating rate (in air).

the DSC profile, the majority of the heat emitted during oxidation occurs immediately after the endotherm of melting (heat input required for the phase transition), which confirms that zinc combustion takes place in the liquid phase. The TGA profile for zinc powder combustion indicates sample weight increase during formation of metal oxide, which is characteristic of metal oxidation. Slight weight decrease, prior to the onset of zinc combustion, occurs at approximately $250{ }^{\circ} \mathrm{C}$ and can be attributed to decomposition of trace impurities within the sample. Integration of the DSC profile over the full zinc combustion temperature range yielded $3617 \pm 217 \mathrm{~J} / \mathrm{g}$ of heat emitted during metal oxidation, which is more than five times the energy produced per gram of cornstarch.
The reader might expect the measured explosibility data shown in Table 2 to correlate directly with the reactivity and severity of combustion. In other words, augmented explosibility parameters would typically lead one to anticipate an increase in the amount of heat released during fuel combustion. This, however, was not the case. In reality, organic cornstarch exhibited a two-fold increase in the $K_{\mathrm{St}}$ during the $1 \mathrm{~m}^{3}$ sphere explosibility testing but released five times less energy per gram than zinc powder during combustion. Metal dusts have higher burning temperatures, heats of combustion, and radiation heat transfer rates compared with organic fuels; therefore, the assessment of severity and spontaneity of metal dust propagation using exclusively the explosibility index $\left(K_{\mathrm{St}}\right)$ is an unreliable means of evaluating overall fuel reactivity.

The amounts of heat absorbed during suppressant agent decomposition, calculated by integration of the DSC heat flow endotherms over both the entire temperature range (from 20 to $1300{ }^{\circ} \mathrm{C}$ ) and the specific fuel combustion range for cornstarch and zinc powder, are shown in Table 4. The TGA and DSC profiles for the agent-only experiments are shown in Figures 6 to 10 and Supporting Information Figures D-1 to D5 , respectively.

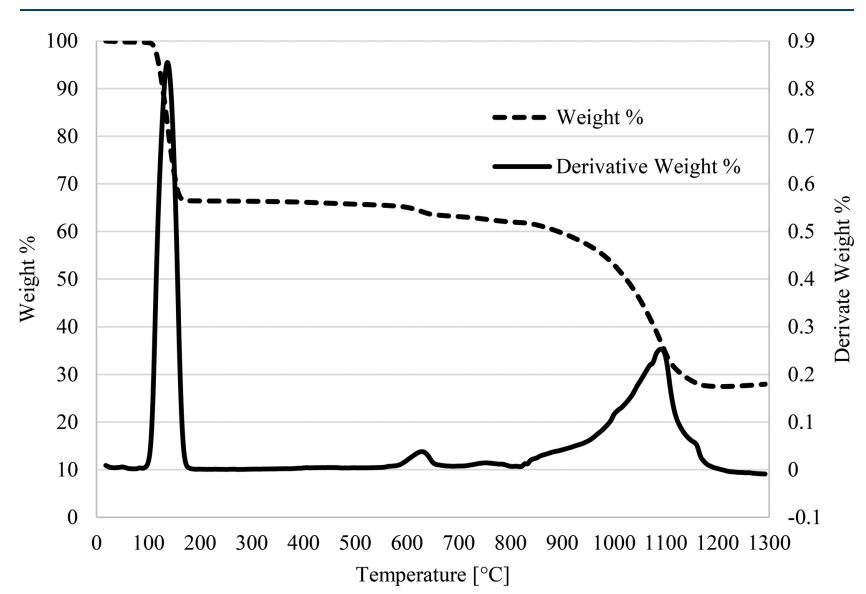

Figure 6. Thermogravimetric profile for sodium bicarbonate inert material. Increase in temperature, from room temperature to $1300{ }^{\circ} \mathrm{C}$, at a constant $10{ }^{\circ} \mathrm{C} / \mathrm{min}$ heating rate (in air).

Inerting agents can be classified as low-, intermediate-, or high-temperature decomposing materials by analyzing the TGA profiles as shown in Figures 6 to 10. For example, the carbonates (SBC and $\mathrm{PK}$ ) demonstrate two regions of decomposition, one initially at relatively low temperature $\left(100\right.$ to $200{ }^{\circ} \mathrm{C}$ ) and another at high temperature ( 850 to 1200 ${ }^{\circ} \mathrm{C}$ ). The phosphates (MAP and DAP) display two regions of decomposition, one at low temperature $\left(100\right.$ to $\left.450{ }^{\circ} \mathrm{C}\right)$ and

Table 4. Predicted Inhibitor Efficiencies Corresponding to Both the Total Temperature Range and the Specific Fuel Combustion Range; Integration of DSC Profiles on Figures D-1, D-2, D-3, D-4, and D-5, from Room Temperature to $1300{ }^{\circ} \mathrm{C}$

$\begin{array}{lccccc}\text { inhibitor } & \begin{array}{c}\text { total endotherm area } \\ {[\mathrm{J} / \mathrm{g}]}\end{array} & \begin{array}{c}\text { avg dev } \\ {[\mathrm{J} / \mathrm{g}]}\end{array} & \begin{array}{c}\text { area over cornstarch combustion range } \\ {[\mathrm{J} / \mathrm{g}]}\end{array} & \begin{array}{c}\text { avg dev } \\ {[\mathrm{J} / \mathrm{g}]}\end{array} & \begin{array}{c}\text { area over zinc combustion range } \\ {[\mathrm{J} / \mathrm{g}]}\end{array} \\ \text { SBC } & -5875 & 91 & -487 & 18 & \begin{array}{c}\text { avg dev } \\ {[\mathrm{J} / \mathrm{g}]}\end{array} \\ \text { PK } & -4970 & 28 & -387 & 69 & -886 \\ \text { MAP } & -3845 & 500 & -680 & -737 & -1 \\ \text { DAP } & -4015 & 354 & -610 & 77 & -1407 \\ \text { Met-L-X } & -5533 & 557 & -439 & 3 & -1173\end{array}$




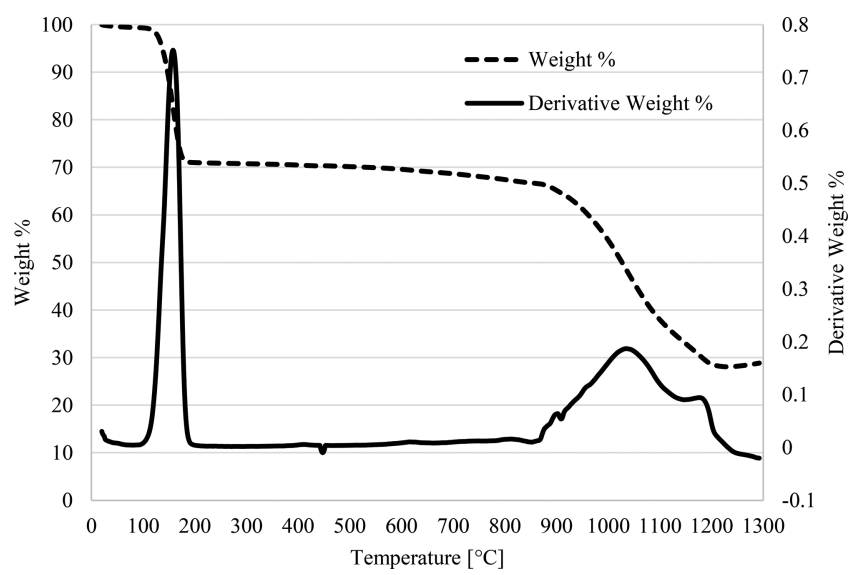

Figure 7. Thermogravimetric profile for potassium bicarbonate inert material. Increase in temperature, from room temperature to $1300{ }^{\circ} \mathrm{C}$, at a constant $10^{\circ} \mathrm{C} / \mathrm{min}$ heating rate (in air).

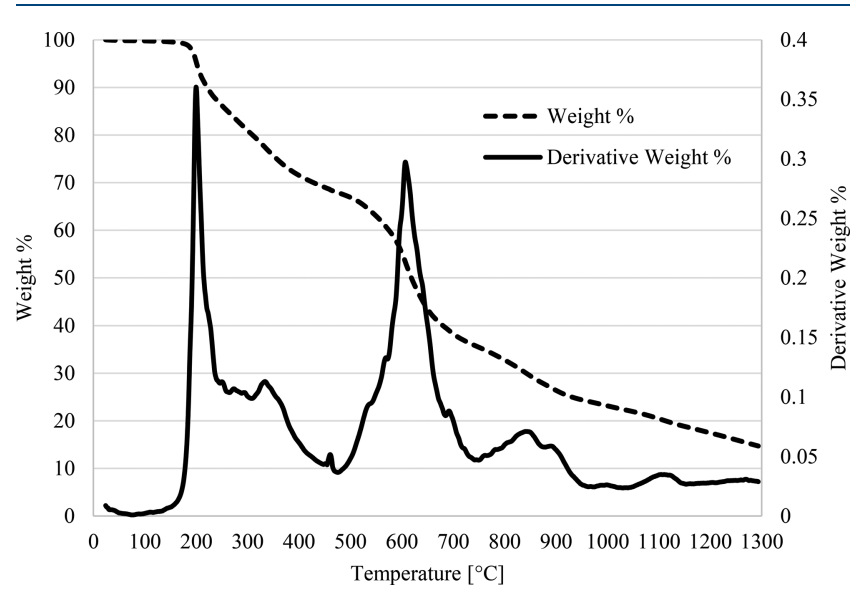

Figure 8. Thermogravimetric profile for monoammonium phosphate inert material. Increase in temperature, from room temperature to $1300{ }^{\circ} \mathrm{C}$, at a constant $10^{\circ} \mathrm{C} / \mathrm{min}$ heating rate (in air).

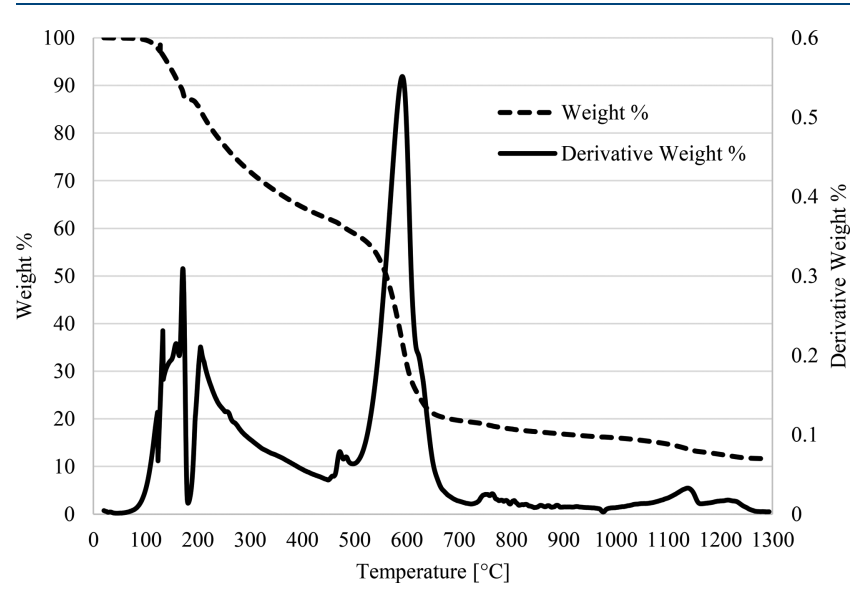

Figure 9. Thermogravimetric profile for diammonium phosphate inert material. Increase in temperature, from room temperature to $1300{ }^{\circ} \mathrm{C}$, at a constant $10{ }^{\circ} \mathrm{C} / \mathrm{min}$ heating rate (in air).

another at intermediate temperature (500 to $\left.750{ }^{\circ} \mathrm{C}\right)$. Sodium chloride (Met-L-X) exhibits a single region of high-temperature endothermic decomposition, with the majority of sample weight loss occurring immediately after the melting point of $\mathrm{NaCl}$, between 800 to $1000{ }^{\circ} \mathrm{C}$. The precise temperature range

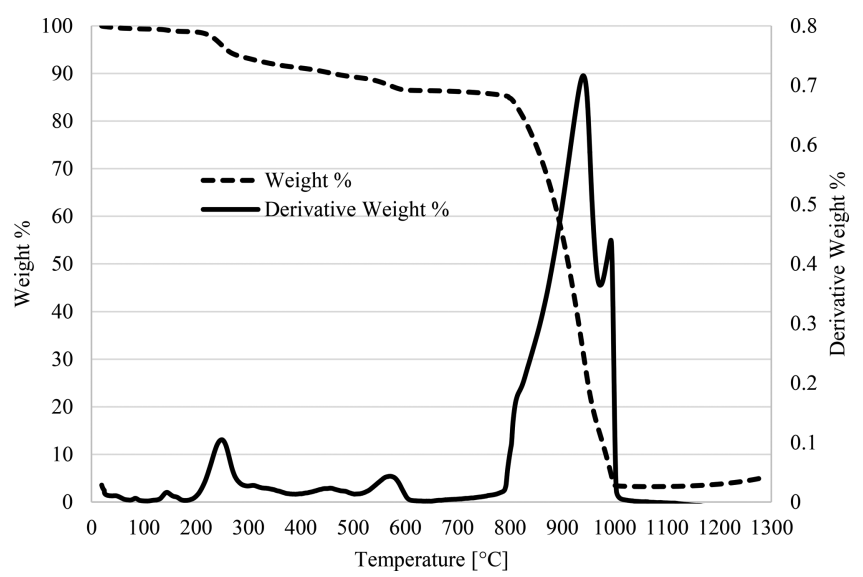

Figure 10. Thermogravimetric profile for Met-L-X inert material. Increase in temperature, from room temperature to $1300{ }^{\circ} \mathrm{C}$, at a constant $10^{\circ} \mathrm{C} / \mathrm{min}$ heating rate (in air).

of inertant degradation relative to the fuel decomposition zone plays a pivotal role in analyzing heat absorption and inhibition performance during fuel combustion. This concept, as well as the mechanisms of inhibitor decomposition, will be investigated in detail in sections 4.2 and 4.3 .

The DSC profiles were analyzed using destructive interference of the fuel exotherms and inhibitor endotherms to calculate the inhibition effectiveness of the suppressant agents over a particular fuel combustion temperature range. This approach provides an understanding of the physical inhibition potential of each inertant and assesses the thermal capacity of the inhibitor to absorb heat from the surroundings. However, this analysis does not gauge the effectiveness of the agents as chemical inhibitors, which is theorized to be dependent on the proximity of the primary inert decomposition temperature range in relation to the fuel combustion zone. As shown in Table 4, inert material PK exhibits the largest magnitude of endotherm area over fuel combustion temperature ranges and therefore demonstrates the greatest potential inhibition performance for both cornstarch and zinc combustion. This hypothesis will be examined in sections 4.2 and 4.3 by analyzing the DSC profiles for the cornstarch/agent and zinc/agent mixtures.

4.2. Analysis of Cornstarch/Inhibitor Mixtures. To validate the predictive outcome mentioned in the previous section, 1:1 wt $\%$ mixtures of cornstarch and inhibitors were analyzed using TGA and DSC. The heat flow signatures for each DSC profile (Figures 11, 12, and 13) were integrated to calculate the amount of heat released during mixture decomposition. The difference between the heat released by the fuel and the heat released by the mixture directly indicates the heat effectively absorbed by the suppressant agent. Lowering of the total heat flow throughout the combustion temperature zone results in a more efficient fuel inhibition during combustion. Prior to integration, all heat flow data were appropriately normalized by treating the cornstarch heat flow signature, before and after the fuel combustion range, as the baseline. The integration results for all cornstarch and inhibitor mixture decompositions are provided in Table 5. Compared to the heat released during exothermic fuel decomposition (659 $\mathrm{J} / \mathrm{g}$ ), potassium bicarbonate (PK) mixed with cornstarch exhibited the lowest heat release $(-850 \mathrm{~J} / \mathrm{g})$ of all five inerting materials tested in this study when integrated from room temperature to $800{ }^{\circ} \mathrm{C}$. The heat absorption performance for 


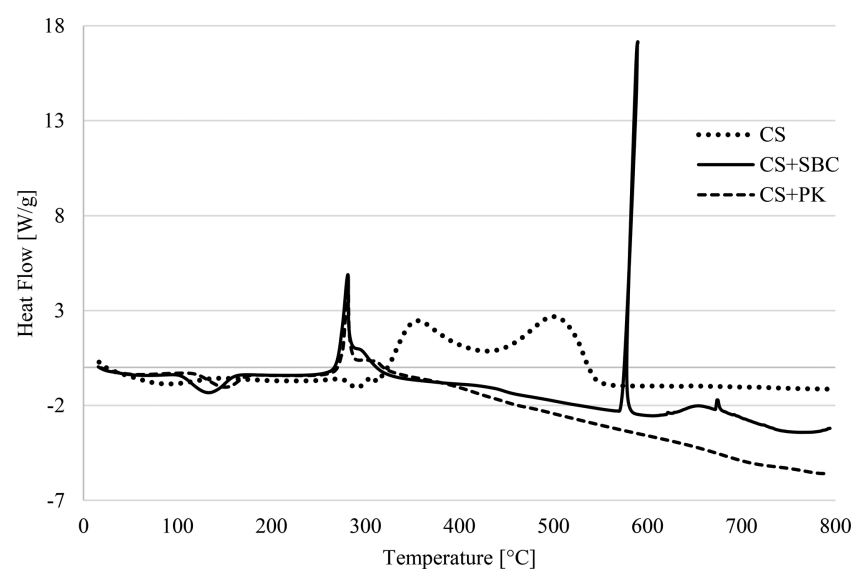

Figure 11. Differential scanning calorimetry profile for cornstarch, mixture of cornstarch and SBC, and mixture of cornstarch and PK. Increase in temperature, from room temperature to $800{ }^{\circ} \mathrm{C}$, at a constant $10{ }^{\circ} \mathrm{C} / \mathrm{min}$ heating rate (in air).

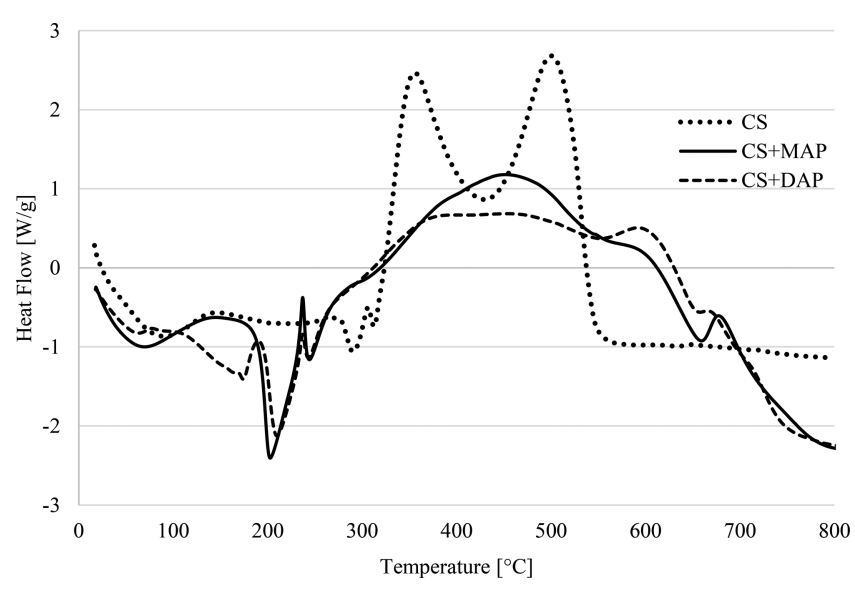

Figure 12. Differential scanning calorimetry profile for cornstarch, mixture of cornstarch and MAP, and mixture of cornstarch and DAP. Increase in temperature, from room temperature to $800{ }^{\circ} \mathrm{C}$, at a constant $10{ }^{\circ} \mathrm{C} / \mathrm{min}$ heating rate (in air).

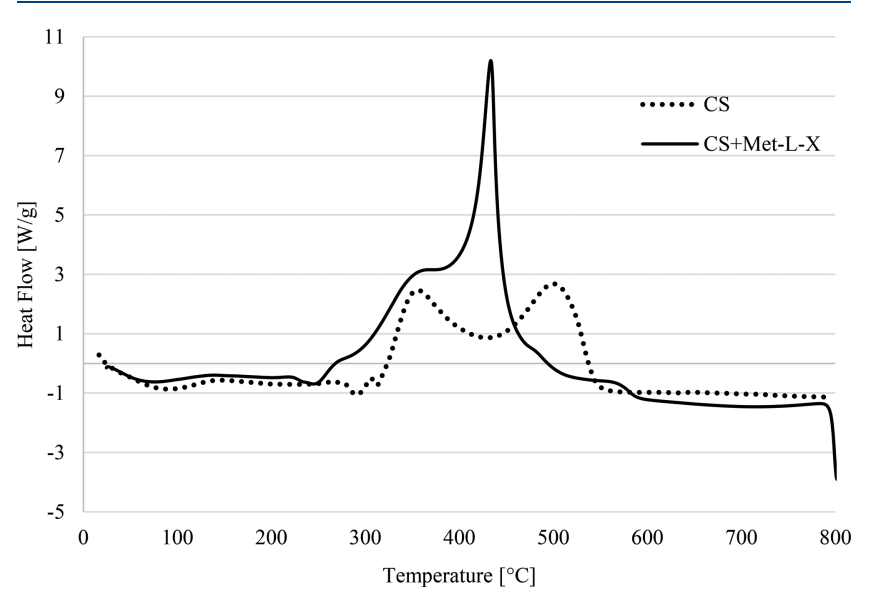

Figure 13. Differential scanning calorimetry profile for cornstarch and mixture of cornstarch and Met-L-X. Increase in temperature, from room temperature to $800{ }^{\circ} \mathrm{C}$, at a constant $10{ }^{\circ} \mathrm{C} / \mathrm{min}$ heating rate (in air).

sodium bicarbonate (SBC), with a mixture heat release of $-184 \mathrm{~J} / \mathrm{g}$, was slightly lower compared to PK.
Table 5. Total Heat Released during Decomposition of Cornstarch and Cornstarch/Inhibitor Mixtures; Normalized Integration of Figures 11, 12, and 13, from Room Temperature to $800{ }^{\circ} \mathrm{C}$

\begin{tabular}{lrc}
$\begin{array}{c}\text { fuel/inhibitor } \\
\text { mixture }\end{array}$ & $\begin{array}{r}\text { normalized DSC curve area } \\
{[\mathrm{J} / \mathrm{g}]}\end{array}$ & $\begin{array}{c}\text { average normalized } \\
\text { deviation }[\mathrm{J} / \mathrm{g}]\end{array}$ \\
\hline CS & 659 & 41 \\
$\mathrm{CS}+\mathrm{SBC}$ & -184 & 1 \\
$\mathrm{CS}+\mathrm{PK}$ & -850 & 139 \\
$\mathrm{CS}+$ MAP & 528 & 1 \\
$\mathrm{CS}+\mathrm{DAP}$ & 681 & 194 \\
CS + Met-L-X & 986 & 61 \\
\hline
\end{tabular}

The DSC profiles for cornstarch and carbonate/cornstarch mixtures are shown in Figure 11. SBC and PK display similar behaviors when allowed to decompose in a $1: 1 \mathrm{wt} \%$ mixture with organic cornstarch. The heat flow profiles for both agent mixtures indicate a catalyzed exothermic mixture decomposition occurring between 250 and $325{ }^{\circ} \mathrm{C}$, which is well before the onset of the characteristic cornstarch combustion range. Not apparent with $\mathrm{PK}$, the DSC profile for the cornstarch and SBC mixture decomposition produces a secondary fuel combustion step, which corresponds to a narrow, high-magnitude exotherm at approximately $570{ }^{\circ} \mathrm{C}$. In regard to the way that these agents behave as the mixture degrades, the main difference between PK and SBC is the slope of the heat signature following the initial heat release for the mixture. For the PK mixture, a greater negative slope signifies that this inert material has an increased capability to absorb exothermic heat from the sustained fuel combustion. For higher fuel to agent mixture ratios, the linear segment approaches a zero slope as the capacity to absorb additional heat decreases. Confirmed by literature and the corresponding TGA profile shown in Figure 7, the degradation mechanism for PK is as follows: ${ }^{17}$

$$
\begin{aligned}
& 2 \mathrm{KHCO}_{3(\mathrm{~s})} \rightarrow \mathrm{K}_{2} \mathrm{CO}_{3(\mathrm{~s})}+\mathrm{CO}_{2(\mathrm{~g})}+\mathrm{H}_{2} \mathrm{O}_{(\mathrm{g})} \\
& \mathrm{K}_{2} \mathrm{CO}_{3(\mathrm{~s})} \rightarrow \mathrm{CO}_{2(\mathrm{~g})}+\mathrm{K}_{2} \mathrm{O}_{(\mathrm{s})}
\end{aligned}
$$

The first inhibitor decomposition step takes place between 100 to $200{ }^{\circ} \mathrm{C}$ and produces water vapor and carbon dioxide, which act as gaseous inert heat sinks and offer mass transport resistance by reducing diffusion of oxygen onto the solid surface by dilution. Potassium carbonate $\left(\mathrm{K}_{2} \mathrm{CO}_{3}\right)$ is the solidstate material present during the cornstarch decomposition temperature range and has a constant pressure molar heat capacity of $114.4 \mathrm{~J} / \mathrm{mol}^{-1} \mathrm{~K}^{-1}$ at $298 \mathrm{~K}$, which is slightly higher than that of sodium carbonate $\left(112.3 \mathrm{~J} / \mathrm{mol}^{-1} \mathrm{~K}^{-1}\right.$ at $\left.298 \mathrm{~K}\right)$ and provides potassium carbonate an advantage for thermal inhibition. $^{30}$ The second step involves the dissociation of potassium carbonate at higher temperatures ( 850 to $1200{ }^{\circ} \mathrm{C}$ ) into potassium oxide. This decomposition step occurs after the cornstarch combustion temperature range and therefore does not affect the inhibition efficiency of the agent. The mechanism for SBC decomposition is identical to that of $\mathrm{PK}$, except for the substitution of $\mathrm{Na}$ for $\mathrm{K}$.

MAP, DAP, and Met-L-X provided minimal inhibition of cornstarch combustion. The DSC profile for the mixture of cornstarch and Met-L-X (shown in Figure 13) illustrates that sodium chloride appears to promote intensified exothermic fuel decomposition, with the mixture releasing more heat (986 $\mathrm{J} / \mathrm{g}$ ) than emitted during cornstarch combustion without 
inhibitor. The inability of these agents to mitigate the fuel combustion can be attributed to the position of their decomposition temperature range. As shown by TGA profiles (Figures 8, 9, and 10), the decomposition of these three agents occurs toward the end of the cornstarch decomposition temperature range (or completely after, as in the case of Met$\mathrm{L}-\mathrm{X}$ ). Principal agent decomposition at temperatures greater than the fuel combustion eliminates the potential for chemical inhibition which can reduce free radicals that sustain continued growth of the propagating flame front. In the case of these three agents, the inhibition is primarily physical; inerting relies solely on the heat capacity, thermal conductivity, and absorptivity of the agent but lacks assistance from gaseous volatiles which would normally impede the combustion kinetically.

Oxidation modes for organic fuels are less complex than those for metal powders. Direct overlap of agent and organic fuel decomposition is not always necessary to achieve effective combustion suppression through only physical inhibition. As long as dissociation of the suppressant agent occurs prior to the onset of fuel combustion, inert gas decomposition products have the potential to complement the thermal absorption properties of the agent or of any other solid state decomposition products. However, metal fuel propagation exhibits increasingly complicated mechanisms of combustion and requires enhanced techniques for inerting, including dependency on chemical inhibition as an effective supplement to standard physical mitigation.

4.3. Analysis of Zinc Powder/Inhibitor Mixtures. Applying the same analytical technique as described in section 4.2, 1:1 wt \% mixtures of zinc powder and inhibitors were assessed using TGA and DSC. Similar to the organic fuel/ agent mixture evaluation, the DSC profiles shown in Figures 14,15 , and 16 were integrated to yield the effective amount of

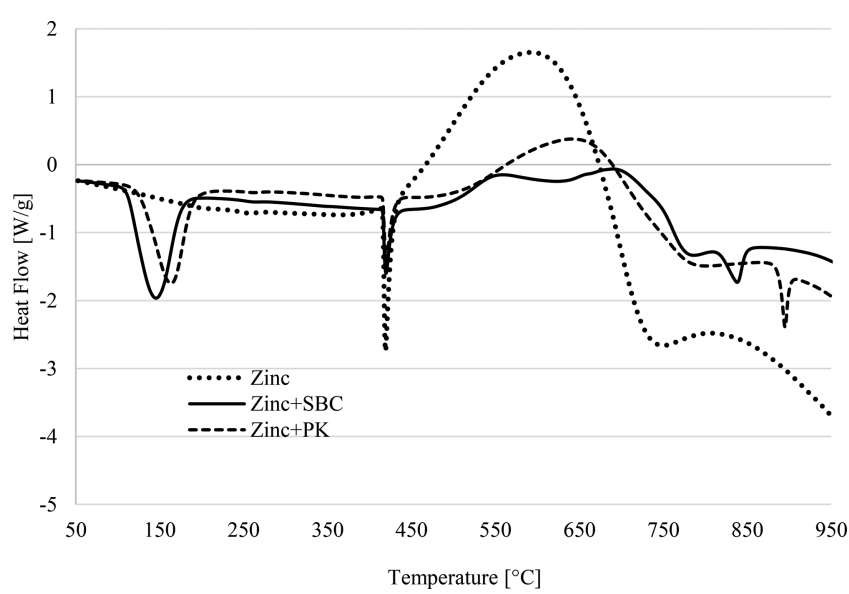

Figure 14. Differential scanning calorimetry profile for zinc powder, mixture of zinc powder and SBC, and mixture of zinc powder and $\mathrm{PK}$. Increase in temperature, from 50 to $950{ }^{\circ} \mathrm{C}$, at a constant $10^{\circ} \mathrm{C} / \mathrm{min}$ heating rate (in air).

heat released (or absorbed) during mixture decomposition. Similar to the analysis of the cornstarch mixtures, lower heat flow during the combustion temperature zone results in a more effective inhibition of fuel combustion. The DSC peak integrations were performed over both the entire temperature range $\left(50\right.$ to $950{ }^{\circ} \mathrm{C}$ ) and the liquid-phase zinc combustion

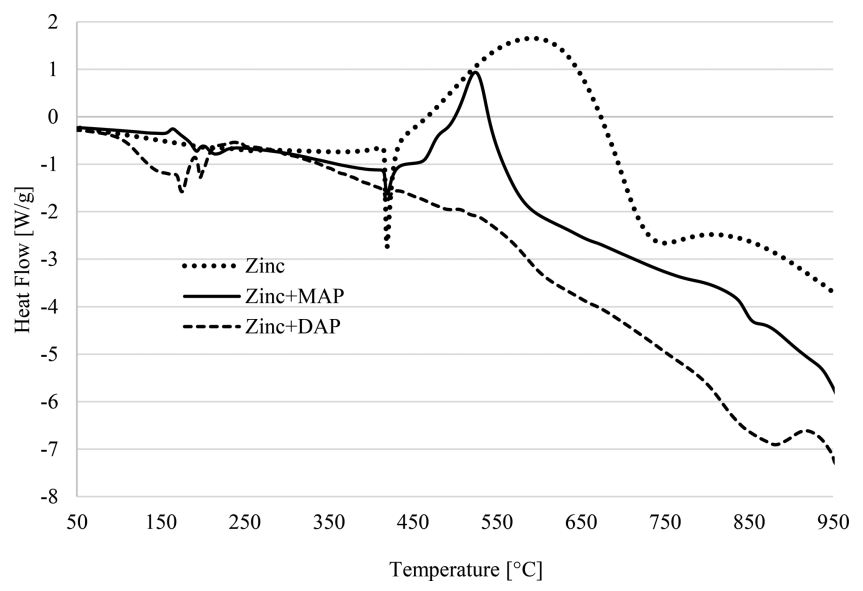

Figure 15. Differential scanning calorimetry profile for zinc powder, mixture of zinc powder and MAP, and mixture of zinc powder and DAP. Increase in temperature, from 50 to $950{ }^{\circ} \mathrm{C}$, at a constant 10 ${ }^{\circ} \mathrm{C} / \mathrm{min}$ heating rate (in air).

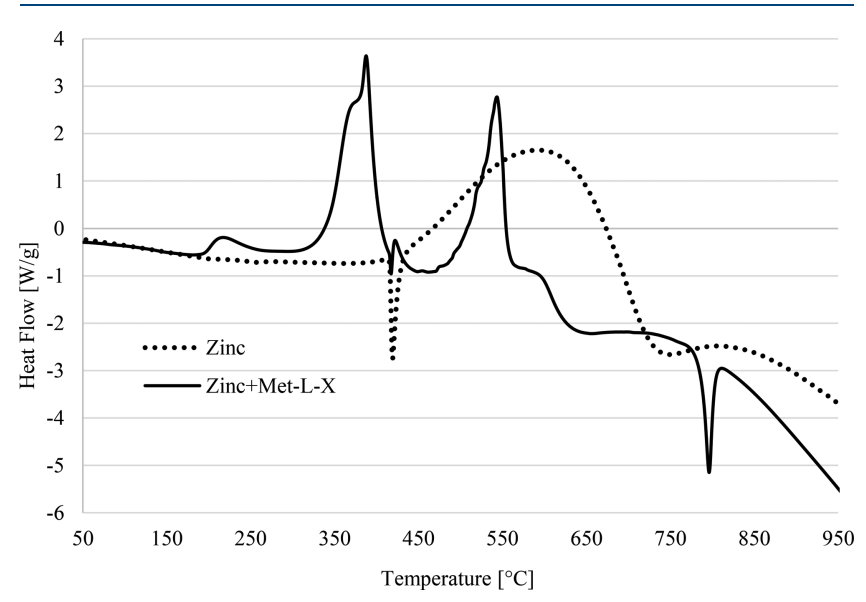

Figure 16. Differential scanning calorimetry profile for zinc powder and mixture of zinc powder and Met-L-X. Increase in temperature, from 50 to $950{ }^{\circ} \mathrm{C}$, at a constant $10{ }^{\circ} \mathrm{C} / \mathrm{min}$ heating rate (in air).

range ( 400 to $750{ }^{\circ} \mathrm{C}$ ). The results of these peak integrations are provided in Table 6.

In comparison to the heat released during zinc decomposition $(3617 \mathrm{~J} / \mathrm{g})$, suppressant candidates $\mathrm{SBC}, \mathrm{PK}$, and Met-L-X demonstrate limited suppression of zinc combustion due to their predisposition toward physical mitigation (agent decomposition only exists before or after the fuel combustion

Table 6. Total Heat Released during Decomposition of Zinc Powder and Zinc/Inhibitor Mixtures; Integration of Figures 14, 15, and 16 over Both the Full Temperature Range (50 to $950{ }^{\circ} \mathrm{C}$ ) and the Zinc Liquid-Phase Combustion Range (400 to $750{ }^{\circ} \mathrm{C}$ )

$\begin{array}{lcrcr}\begin{array}{c}\Sigma \text { (All DSC } \\ \text { fuel/inhibitor } \\ \text { mixture }\end{array} & \begin{array}{c}\text { avg } \\ \text { curve peak } \\ \text { areas) }[\mathrm{J} / \mathrm{g}]\end{array} & \begin{array}{c}\sum \text { (peak areas within } \\ \text { dev } \\ {[\mathrm{J} / \mathrm{g}]}\end{array} & \begin{array}{c}\text { avg } \\ \text { combustion range) } \\ \text { [J/g] }\end{array} & \begin{array}{r}\text { dev } \\ {[\mathrm{J} / \mathrm{g}]}\end{array} \\ \mathrm{Zn} & 3617 & 217 & 3617 & 433 \\ \mathrm{Zn}+\mathrm{SBC} & 715 & 12 & 1149 & 14 \\ \mathrm{Zn}+\mathrm{PK} & 985 & 48 & 1342 & 49 \\ \mathrm{Zn}+\text { MAP } & 627 & 140 & 806 & 84 \\ \text { Zn + DAP } & -247 & 184 & 203 & 46 \\ \text { Zn + Met-L-X } & 2267 & 59 & 1243 & 41\end{array}$


range). Heat flow signatures for zinc powder mixed with carbonate inhibitors, SBC and PK, are shown in Figure 14. The primary mixture combustion exotherm is within the original zinc oxidation temperature range. Relying on physical inhibition (as discussed for SBC and PK in section 4.2) worked well for cornstarch (organic combustion) mitigation but only slightly reduces the quantity of heat released for zinc powder combustion. The DSC profile for zinc powder mixed with the Met-L-X inhibitor is shown in Figure 16. The agent appears to catalyze the onset of fuel combustion at lower temperatures and does little to reduce the exothermic heat released during fuel decomposition. Liquid-phase sodium chloride decomposition in the mixture occurred after the metal combustion (between the melting point of 800 and 1100 ${ }^{\circ} \mathrm{C}$ ), therefore eliminating the potential for partial chemical inhibition. The unexceptional efficiency of sodium chloride as a suppressant for zinc combustion depends solely on the thermal absorption properties of the agent (constant pressure heat capacity of $50.5 \mathrm{~J} / \mathrm{mol}^{-1} \mathrm{~K}^{-1}$ at $\left.298 \mathrm{~K}\right) .^{30}$

Phosphate-based suppressant agents MAP and DAP exhibit substantially improved suppression performance, reducing the quantity of heat released over the fuel combustion range to 806 $\mathrm{J} / \mathrm{g}$ and $203 \mathrm{~J} / \mathrm{g}$, respectively, as shown in Figure 15. When the DAP and zinc mixture is heated, the principal exothermic peak is nearly nonexistent, essentially demonstrating full suppression of the fuel oxidation. The efficiency of combustion mitigation can also be assessed by examining the increase in the mass of the mixture as zinc oxide is generated (see zinc/inhibitor TGA profiles in the Supporting Information, Appendix B). Larger percent mass increase during zinc combustion indicates that the reaction progresses uninterrupted and that the inhibitor is less effective in dampening the oxidation rate. During combustion, mixtures of zinc fuel with DAP, MAP, SBC, and PK demonstrate an equivalent rise in mixture mass percent of $4,7,9$, and 11 wt \%, respectively. This trend of increasing weight change during the combustion zone correlates well with the increase in heat released (and decrease in inhibition effectiveness), as shown by the integration results in Table 6 . Amplified heat of absorption efficiency for MAP and DAP can be explained in part by the corresponding agent decomposition mechanism: ${ }^{24}$

$$
\begin{aligned}
& \left(\mathrm{NH}_{4}\right)_{2} \mathrm{HPO}_{4(\mathrm{~s})} \rightarrow \mathrm{NH}_{3(\mathrm{~g})}+\mathrm{NH}_{4} \mathrm{H}_{2} \mathrm{PO}_{4(\mathrm{~s})} \\
& \left(\mathrm{NH}_{4}\right)_{2} \mathrm{HPO}_{4(\mathrm{~s})} \rightarrow 2 \mathrm{NH}_{3(\mathrm{~g})}+\mathrm{H}_{3} \mathrm{PO}_{4(\mathrm{l})} \\
& \mathrm{NH}_{4} \mathrm{H}_{2} \mathrm{PO}_{4(\mathrm{~s})} \rightarrow \mathrm{NH}_{3(\mathrm{~g})}+\mathrm{H}_{3} \mathrm{PO}_{4(\mathrm{l})} \\
& 4 \mathrm{H}_{3} \mathrm{PO}_{4(\mathrm{l})} \rightarrow 2 \mathrm{H}_{2} \mathrm{O}_{(\mathrm{g})}+2 \mathrm{H}_{4} \mathrm{P}_{2} \mathrm{O}_{7(\mathrm{l})} \\
& 2 \mathrm{H}_{4} \mathrm{P}_{2} \mathrm{O}_{7(\mathrm{l})} \rightarrow 4 \mathrm{H}_{2} \mathrm{O}_{(\mathrm{g})}+\mathrm{P}_{4} \mathrm{O}_{10(\mathrm{~s})}
\end{aligned}
$$

Reaction mechanism steps E3 to E7 are applicable for DAP decomposition, while MAP dissociation occurs via steps E5 to E7. In comparison to MAP, DAP has a larger constant pressure molar heat capacity $\left(141.4 \mathrm{~J} / \mathrm{mol}^{-1} \mathrm{~K}^{-1}\right.$ and $188 \mathrm{~J} / \mathrm{mol}^{-1} \mathrm{~K}^{-1}$ for MAP and DAP, respectively, at $298 \mathrm{~K}$ ) and greater potential for physical heat absorption. ${ }^{30,31}$ Both sets of decomposition reactions produce the inert gas ammonia (as per reaction stoichiometry, four times more ammonia generation following DAP dissociation), which acts as a buffer against sustained mass and heat transfer on the particle surface. Obstruction of active reaction sites successfully limits diffusion of oxygen, restricting continued fuel particle preheating and volatilization. In industrial prevention or mitigation applications, this corresponds to arrested flame temperatures and lower concentrations of oxidant, which thereby introduces significant ignition time delay. However, the ability to inhibit chemically, combined with the aforementioned physical inhibition characteristics, is what distinguishes the performance of MAP and DAP. The degree of chemical inhibition corresponds to the proximity of principal inert decomposition in relation to the fuel combustion zone. Since the primary agent decomposition (approximately 35\% reduction of total sample weight for MAP and $45 \%$ reduction of total sample weight for DAP, as supported by TGA profiles in Figures 8 and 9 , respectively) directly overlaps with the fuel combustion temperature zone ( 400 to $750{ }^{\circ} \mathrm{C}$ ), intermediate species of ammonia and amino radicals are actively present to consume oxygen and other free radicals $(\cdot \mathrm{OH}, \cdot \mathrm{O}, \cdot \mathrm{H})$ that would normally prolong fuel propagation. Although these intermediate reactants and products exist in low concentrations due to their relative instability, radical-consuming intermediate reactions compete for oxygen and are nevertheless vital for enhancing the efficiency of chemical inhibition. Unlike the mixture trials containing SBC or $\mathrm{PK}$, greater availability of oxygen-consuming intermediate reactions during MAP and DAP decomposition allows for reduced oxygen radical concentrations within the reaction zone, resulting in restricted exothermic heat release. ${ }^{19}$ Examples of such transient intermediate mechanisms are shown in eqs E8 to E12:

$$
\begin{aligned}
& \mathrm{NH}_{3}+\cdot \mathrm{OH} \rightarrow \cdot \mathrm{NH}_{2}+\mathrm{H}_{2} \mathrm{O} \\
& \mathrm{NH}_{3}+\cdot \mathrm{H} \rightarrow \cdot \mathrm{NH}_{2}+\mathrm{H}_{2} \\
& \mathrm{NH}_{3}+\cdot \mathrm{O} \rightarrow \cdot \mathrm{NH}_{2}+\cdot \mathrm{OH} \\
& \cdot \mathrm{NH}_{2}+\mathrm{O}_{2} \rightarrow \mathrm{NHO}+\cdot \mathrm{OH} \\
& \cdot \mathrm{NH}_{2}+\cdot \mathrm{O} \rightarrow \cdot \mathrm{NH}+\cdot \mathrm{OH}
\end{aligned}
$$

\section{KINETIC ANALYSIS OF FUEL COMBUSTION}

Estimation of the kinetic parameters for the exothermic combustion of cornstarch and zinc is necessary for understanding of the spontaneity of these fuel decomposition reactions. According to ASTM E698, the relationship between fluctuation in heating rate and corresponding shift in ignition temperature can be used to approximate the Arrhenius kinetic constants for thermally ignitable materials. ${ }^{32,33}$ To apply this standard, the combustion reaction of both cornstarch and zinc was assumed to follow first-order reaction kinetics. For both fuels, multiple DSC profiles were compiled at heating rates $(\beta)$ of $5{ }^{\circ} \mathrm{C} / \mathrm{min}, 10^{\circ} \mathrm{C} / \mathrm{min}, 20^{\circ} \mathrm{C} / \mathrm{min}$, and $30^{\circ} \mathrm{C} / \mathrm{min}$, and the maximum exotherm peak temperatures $\left(T_{\mathrm{MAX}}\right)$ were recorded. Cornstarch decomposition consists of two primary peaks along the exotherm, and zinc powder decomposition consists of a single primary peak along the exotherm, as shown by DSC in Figures 3 and 5, respectively. On the basis of these data sets, plots of $-\ln \left(\beta / T_{\text {MAX }}^{2}\right)$ versus $1 / T_{\text {MAX }}$ were created for each peak. The data were fitted with a linear trend line, and the activation energy $\left(E_{\mathrm{a}}\right)$ for each decomposition peak was determined using the slope, as shown below in eq E13:

$$
\text { slope }=-\frac{E_{\mathrm{a}}}{R}
$$

where $R$ is the gas constant. The assumption of first-order kinetics was confirmed based on the linearity of the data 
Table 7. Calculated Activation Energies and Thermodynamic State Quantities for Cornstarch and Zinc Combustion, Corresponding to Analysis of DSC Heat Signatures by Means of the Technique Documented within ASTM E698 and through Utilization of the Eyring-Polanyi Equation. ${ }^{33-35}$

$\begin{array}{lcccc}\text { DSC Peak } & E_{\mathrm{a}}[\mathrm{kJ} / \mathrm{mol}] & \Delta H[\mathrm{~kJ} / \mathrm{mol}] & \Delta S[\mathrm{~J} / \mathrm{K} / \mathrm{mol}] & \Delta G[\mathrm{~kJ} / \mathrm{mol}] \\ \text { CS Peak } 1 & 20.4 & 21.2 & -217.1 & 167.8 \\ \text { CS Peak 2 } & 60.3 & 60.5 & -149.6 & 179.4 \\ \text { zinc powder } & 41.9 & 41.5 & -207.5 & 232.0\end{array}$

points. The pre-exponential factor $(A)$ was calculated using eq E14 as described in ASTM E698: ${ }^{32,33}$

$$
A=\beta \frac{E_{\mathrm{a}}}{R T_{\max }^{2}} \mathrm{e}^{E_{\mathrm{a}} / R T_{\max }}
$$

The rate constant $(k)$, as a function of system temperature, can be calculated using the activation energy and pre-exponential factor, as shown in eq E15:

$$
k=A e^{-E_{\mathrm{a}} / R T}
$$

Once correlations for rate constants were established for each exotherm peak, transition state theory and the Eyring-Polanyi equation (eq E16) were utilized, in which $k_{\mathrm{B}}$ and $h$ represent the Boltzmann's constant and Planck's constant, respectively. ${ }^{32-34}$ A plot of $-\ln \left(k / T_{\mathrm{MAX}}\right)$ versus $1 / T_{\mathrm{MAX}}$ was generated for all exotherm peaks. Following linear fitting of the data, the slope was utilized to determine the enthalpy of activation $(\Delta H)$, and the $y$-intercept was utilized to determine the entropy of activation $(\Delta S)$.

$$
\ln \left(\frac{k}{T_{\max }}\right)=-\frac{\Delta H}{R} \frac{1}{T_{\max }}+\ln \left(\frac{k_{\mathrm{B}}}{h}\right)+\frac{\Delta S}{R}
$$

The Gibbs free energy of activation $(\Delta G)$ for each decomposition peak can then be calculated using the following thermodynamic relationship:

$$
\Delta G=\Delta H-T \Delta S
$$

Positive values for Gibbs free energy of activation represent an endergonic reaction, in which the system requires an input of energy. In a dynamic combustion environment, larger values for $\Delta G$ signify more free energy available to promote flame front propagation and heating of surrounding particles. The activation entropy describes how energy must be redistributed through the molecule before reaction initiation is able to occur. Molecular geometry, orientation in space, and viable degrees of freedom exhibit substantial influence on the entropy of activation. Transition state theory offers explanation for rates of elementary reactions by assuming quasi-chemical equilibrium between reactants and higher-energy activated transition state complexes. ${ }^{34,35}$ In support of this concept, activation enthalpy signifies the change in enthalpy from the initial reactant state to the reactant-product hybrid transition state and is typically comparable in magnitude to the activation energy $\left(E_{\mathrm{a}}\right)$. Higher values of activation enthalpy and activation energy indicate a reduced reaction rate, as is the case for the second peak in cornstarch decomposition (see TGA profile, Figure 3). This peak represents incomplete combustion and leads to formation of carbon monoxide due to the insufficient presence of oxidizer and poor mixing of the fuel/air interface. Utilizing methodology from ASTM E698 followed by application of the Eyring-Polanyi equation, kinetic parameters and thermodynamic state functions were modeled for all fuel combustion peaks and are shown in Table 7.
Other modeling techniques can be additionally employed to assess the degree of combustion rate control by diffusion and kinetics. The shrinking particle model is commonly utilized for simplistic noncatalytic irreversible first-order reactions between solid fuel and surrounding gas film. Another more complicated technique, known as the shrinking unreacted core model, assumes that a reaction front moves from the surface through the solid particle interior and leaves behind a permeable product layer. Unlike the previous model which only considered the chemical reaction rate and diffusion of oxygen through the gas film boundary, the shrinking unreacted core model takes diffusion through a porous product layer (between the gas film and unreacted solid core) into account as well. Depending on the combination of transport and kinetic resistances, a principal aim of these models is to establish correlations for fuel burnout time. From an application standpoint, longer particle burning durations require extended suppressant agent discharge, such that the inertant injection continues for the entirety of the fuel combustion. Such considerations are crucial to large-scale mitigation designs, especially when suppressant agents of varying packed densities tend to exhibit unique dispersion rates and cloud profiles.

\section{CONCLUSIONS}

Metal dusts continue to present a significant threat in a large variety of process industries. Utilizing the heat flow signature of pure metal fuel sample as a reference, peak integration analysis yields that the 1:1 wt \% mixture of diammonium phosphate (DAP) and zinc powder demonstrated the greatest reduction in exothermic heat release in comparison to other inertant materials tested. The majority of the endothermic decomposition of DAP occurs over the same temperature range during which zinc combusts (zinc propagates exclusively in the liquid phase, from $420{ }^{\circ} \mathrm{C}$ melting point to approximately $750{ }^{\circ} \mathrm{C}$ ). Similar decomposition temperature ranges for the fuel and agent provide greater potential to inhibit combustion chemically through consumption of free radicals that would ordinarily sustain ongoing fuel propagation. The results of this study support the need for explosion protection design solutions which exploit particular suppressant materials and are uniquely tailored toward specific fuel types.

The overlap of fuel and agent decomposition temperature ranges increases the inhibition effectiveness of the agent and brings industrial applications closer to a refined solution for preventative inerting and active explosion mitigation. The next steps include large-scale suppression testing in a $1 \mathrm{~m}^{3}$ sphere explosion test vessel in order to validate conclusions based on this lab-scale analytical study. Results pertaining to this work are in progress and will be published at a later date. An increase in chemical inhibition moderates the necessity for physical (thermal) inhibition. For deflagration mitigation through active suppression, this corresponds to lower agent concentrations required to achieve tolerable suppression pressures 
after system activation. If performance can be maintained by using reduced quantities of inertant material and less associated hardware, this provides a less expensive and thus more attractive option for customers conveying reactive metal dusts. Currently, active suppression designs for metal dust fuels commonly utilize SBC at high concentrations, attempting to compensate physically for the agent's lack of chemical inhibition capability. Material flow properties such as gas permeability, bulk density, cohesiveness, floodability, and compressibility are important characteristics to consider for effectively dispersing agents into the protected volume during high-rate pressurized injection following the onset of fuel ignition.

The notion of heightened chemical inhibition due to overlap of the decomposition temperature range can be applied to other fuel types. For example, iron and aluminum powder make up a large percentage of explosion protection applications in recent years. According to literature, solidphase oxidation of iron powder (4 to $10 \mu \mathrm{m}$ iron particle size) generates $5435 \mathrm{~J} / \mathrm{g}$ of heat, with the maximum combustion heat flow occurring at approximately $489^{\circ} \mathrm{C} .{ }^{32}$ As with the labscale zinc inhibition studies described in this work, inertants MAP and DAP exhibit endothermic decomposition temperatures which overlay commendably atop the iron propagation temperature range and would likely offer effective inhibition of iron combustion. Aluminum powder displays a progressively complex and spontaneous combustion mechanism due to failure of the particulate oxide shell at measured ignition temperatures as high as $2100{ }^{\circ} \mathrm{C}$.,36 As demonstrated in the TGA profile for Met-L-X (Figure 10), sodium chloride decomposition is shifted toward higher temperatures (800 to $1000{ }^{\circ} \mathrm{C}$ ), amplifying the probability for chemical inhibition during high-temperature aluminum powder combustion decomposition. Inhibition materials best-suited for inerting and mitigation of iron and aluminum fuel propagation are currently under investigation using analytical and corroborative large-scale testing.

As described in NFPA 69, active explosion suppression designs shall be based on the following key factors: time required for detection, suppressant discharge pattern, suppressant concentrations as a function of time (injection duration), suppressant efficiency, explosibility of the combustible materi$\mathrm{al}$, and physical characteristics of the protected enclosure. ${ }^{37} \mathrm{~A}$ majority of these variables are limited by the hardware of the explosion protection system manufacturer or by the application in question, but the fourth item in this list (suppressant efficiency) is predominantly dependent on inertant physical and chemical inhibition capacity, which acts as the primary focus of this study. In light of escalating doubts about the scalability of $20 \mathrm{~L}$ and $1 \mathrm{~m}^{3}$ sphere explosibility and inerting testing, this work offers a novel analytical technique for characterization and screening of suppression agents based on efficiencies predicted through integration of fuel and fuel/agent mixture heat flow profiles. ${ }^{38,39}$

\section{ASSOCIATED CONTENT}

\section{S Supporting Information}

The Supporting Information is available free of charge on the ACS Publications website at DOI: 10.1021/acs.iecr.8b06143.

Thermogravimetric profiles; particle size distribution; DSC profiles (PDF)

\section{AUTHOR INFORMATION}

\section{Corresponding Author}

*Tel.: (785) 864-6719. E-mail: mark.b.shiflett@ku.edu. ORCID $\odot$

Nicholas S. Reding: 0000-0002-3905-487X

Mark B. Shiflett: 0000-0002-8934-6192

\section{Notes}

The authors declare no competing financial interest.

\section{ACKNOWLEDGMENTS}

This project recognizes the efforts of Rachel Speckin, Edward Reyes, and David Treviño for their experimental contributions, as well as the efforts of Dr. David Minnick for his invaluable assistance with TGA/DSC instrument training, calibration, and troubleshooting. We also thank Fike Corporation for supporting the study and for procuring all fuel and agent materials tested in this analysis.

\section{REFERENCES}

(1) U.S. Chemical Safety and Hazard Investigation Board. Investigation Report No. 2004-01-I-IN; Hayes Lemmerz International, Inc.: Huntington, IN, 2003.

(2) U.S. Chemical Safety and Hazard Investigation Board. Case Study No. 2011-3-I-WV; AL Solutions, Inc.: New Cumberland, WV, 2010.

(3) Li, G.; Yang, H.-X.; Yuan, C.-M.; Eckhoff, R. K. A catastrophic aluminum-alloy dust explosion in China. J. Loss Prev. Process Ind. 2016, 39, 121-130.

(4) Reding, N.; Shiflett, M. B. Metal Dust Explosion Hazards: A Technical Review. Ind. Eng. Chem. Res. 2018, 57 (34), 11473-11482.

(5) Taveau, J. Combustible Metal Dusts: A Particular Class. In 17th Annual International Symposium; Mary Kay O'Connor Process Safety Center, College Station, TX, Oct 28-30, 2014; pp 594-606.

(6) Eckhoff, R. K. Dust Explosions in the Process Industries, $3^{\text {rd }}$ ed.; Gulf Professional Publishing: Amsterdam, 2003.

(7) Ogle, R. A. Dust Explosion Dynamics; Elsevier: Warrenville, IL, 2017.

(8) Chatrathi, K.; Going, J. Dust Deflagration Extinction. Process Saf. Prog. 2000, 19 (3), 146-153.

(9) Dastidar, A. G.; Amyotte, P. R.; Pegg, M. J. Factors influencing the suppression of coal dust explosions. Fuel 1997, 76 (7), 663-670.

(10) Amyotte, P. R. Solid inertants and their use in dust explosion prevention and mitigation. J. Loss Prev. Process Ind. 2006, 19, 161173.

(11) Jiang, H.; Bi, M.; Gao, W.; Gan, B.; Zhang, D.; Zhang, Q. Inhibition of aluminum dust explosions by $\mathrm{NaHCO}_{3}$ with different particle size distributions. J. Hazard. Mater. 2018, 344, 902-912.

(12) Chen, X.; Zhang, H.; Chen, X.; Liu, X.; Niu, Y.; Zhang, Y.; Yuan, B. Effect of dust explosion suppression by sodium bicarbonate with different granulometric distribution. J. Loss Prev. Process Ind. 2017, 49, 905-911.

(13) Rockwell, S.; Taveau, J. Studying the Effect of Sodium Bicarbonate on Hybrid Flames: Burner vs. 20-L sphere experiments. In Proceedings of the Twelfth International Symposium on Hazards, Prevention and Mitigation of Industrial Explosions, Kansas City, MO, USA, Aug 12-17, 2018.

(14) Going, J.; Snoeys, J. Explosion Protection with Metal Dust Fuels. Process Saf. Prog. 2002, 21 (4), 305-312.

(15) Taveau, J.; Vingerhoets, J.; Snoeys, J.; Going, J.; Farrell, T. Suppression of metal dust deflagrations. J. Loss Prev. Process Ind. 2015, 36, 244-251.

(16) Taveau, J.; Vingerhoets, J.; Snoeys, J.; Going, J.; Farrell, T. Explosion Protection with Metal Dust Fuels: New Experimental Evidence. In Proceedings of the Seventh International Seminar on Fire and Explosion Hazards, Providence, RI, USA, May 5-10, 2013. 
(17) Kuang, K.; Chow, W. K.; Ni, X.; Yang, D.; Zeng, W.; Liao, G. Fire suppressing performance of superfine potassium bicarbonate powder. Fire Mater. 2011, 35, 353-366.

(18) Horacek, H.; Grabner, R. Advantages of flame retardants based on nitrogen compounds. Polym. Degrad. Stab. 1996, 54, 205-215.

(19) Jiang, H.; Bi, M.; Li, B.; Gao, W. Inhibition of aluminum dust explosion by $\mathrm{NH}_{4} \mathrm{H}_{2} \mathrm{PO}_{4}$ and $\mathrm{NaHCO}_{3}$. In Proceedings of the Twelfth International Symposium on Hazards, Prevention and Mitigation of Industrial Explosions, Kansas City, MO, USA, Aug 12-17, 2018.

(20) Luo, X.; Wang, T.; Ren, J.; Deng, J.; Shu, C.; Huang, A.; Cheng, F.; Wen, Z. Effects of ammonia on the explosion and flame propagation characteristics of methane-air mixtures. J. Loss Prev. Process Ind. 2017, 47, 120-128.

(21) Moore, P. E. Suppressants for the control of industrial explosions. J. Loss Prev. Process Ind. 1996, 9 (1), 119-123.

(22) Amrogowicz, J.; Kordylewski, W. Effectiveness of dust explosion suppression by carbonates and phosphates. Combust. Flame 1991, 85 (3-4), 520-522.

(23) Camino, G.; Costa, L.; Trossarelli, L. Study of the mechanism of intumescence in fire retardant polymers: Part V - Mechanism of formation of gaseous products in the thermal degradation of ammonium polyphosphate. Polym. Degrad. Stab. 1985, 12 (3), 203-211.

(24) Castellanos, D.; Lewandowski, A.; Diaz, A.; Mejia, A.; Carreto, V.; Mashuga, C.; Rangwala, A.; Cheng, Z.; Mannan, M. Influence of Particle Size and Crystalline Level on the Efficiency of Dust Explosion Inhibitors. Ind. Eng. Chem. Res. 2014, 53, 11527-11537.

(25) Zalosh, R. Metal hydride fires and fire suppression agents. J. Loss Prev. Process Ind. 2008, 21, 214-221.

(26) NFPA 484: Standard for Combustible Metals; National Fire Protection Association: Quincy, MA, 2015.

(27) Cao, X.; Ren, J.; Zhou, Y.; Wang, Q.; Gao, X.; Bi, M. Suppression of methane/air explosion by ultrafine water mist containing sodium chloride additive. J. Hazard. Mater. 2015, 285, 311-318.

(28) ASTM E1226, Standard Test Method for Explosibility of Dust Clouds; The American Society of Mechanic Engineers: West Conshohocken, PA, 2010.

(29) Poletaev, N. I.; Khlebnikova, M. Y.; Khanchych, K. Y. Producing and properties of zinc dust flames. Combust. Sci. Technol. 2018, 190 (6), 1096-1109.

(30) CRC Handbook of Chemistry and Physics, 86th ed.; Lide, D. R., Ed.; CRC Press: Boca Raton, FL, 2005.

(31) Stephenson, C. C.; Zettlemoyer, A. C. The heat capacity of ammonium dihydrogen phosphate from 15 to $300 \mathrm{~K}$. The anomaly at the Curie temperature. J. Am. Chem. Soc. 1944, 66 (8), 1405-1408.

(32) Huang, D. H.; Tran, T. N.; Yang, B. Investigation on the reaction of iron powder mixture as a portable heat source for thermoelectric power generators. J. Therm. Anal. Calorim. 2014, 116 (2), 1047-1053.

(33) ASTM E698, Standard Test Method for Arrhenius Kinetic Constants for Thermally Unstable Materials Using Differential Scanning Calorimetry and the Flynn/Wall/Ozawa Method; The American Society of Mechanic Engineers: West Conshohocken, PA, 2001.

(34) Eyring, H. The activated complex in chemical reactions. J. Chem. Phys. 1935, 3, 107-115.

(35) Evans, M. G.; Polanyi, M. Some applications of the transition state method to the calculation of reaction velocities, especially in solutions. Trans. Faraday Soc. 1935, 31, 875-894.

(36) Beckstead, M. W. A Summary of Aluminum Combustion. In Internal Aerodynamics in Solid Rocket Propulsion; Rhode-Saint-Genèse: Belgium, May 27-31, 2002.

(37) NFPA 69: Standard on Explosion Prevention Systems; National Fire Protection Association: Quincy, MA, 2014.

(38) Cashdollar, K. L. Overview of dust explosibility characteristics. J. Loss Prev. Process Ind. 2000, 13, 183-199.

(39) Dastidar, A. G. Influence of Scale on the Inerting of Dust Explosions. Ph.D. Dissertation, Dalhousie University, 2004. 